\section{National Latino AIDS Awareness Day - October 15, 2015}

National Latino AIDS Awareness Day is observed each year on October 15 to focus on the continuing and disproportionate impact of human immunodeficiency virus (HIV) infection and acquired immunodeficiency syndrome (AIDS) on the Hispanic or Latino population in the United States. Hispanics or Latinos represent approximately $17 \%$ of the U.S. population (1); however, in 2013, they accounted for $21 \%$ of all new diagnoses, corresponding to a rate of 18.7 per 100,000 (2). In 2011, an estimated 242,000 Hispanics or Latinos were living with HIV infection in the United States, representing $20 \%$ of all such persons. Of these Hispanics or Latinos, an estimated $85 \%$ had received a diagnosis of HIV infection, $40 \%$ were engaged in HIV medical care, $37 \%$ had received a prescription for antiretroviral therapy, and 31\% had achieved viral suppression (3).

National Latino AIDS Awareness Day is an opportunity to encourage increased HIV prevention activities, such as HIV testing, for Hispanics or Latinos. CDC supports testing, linkage to and engagement in care and treatment, and a range of other efforts to reduce the risk for acquiring or transmitting HIV infection among Hispanics or Latinos. Additional information about CDC resources and activities for National Latino AIDS Awareness Day is available at http://www.cdc. gov/Features/LatinoAIDSAwareness. Additional information about HIV among Hispanics or Latinos is available at http:// www.cdc.gov/hiv/risk/racialethnic/hispanicslatinos.

\section{References}

1. US Census Bureau. Population estimates. Available at http://www. census.gov/popest/data.

2. CDC. Diagnoses of HIV infection in the United States and dependent areas, 2013. HIV Surveillance Report 2015(25). Available at http://www.cdc.gov/hiv/library/reports/surveillance/2013/ surveillance_report_vol_25.html.

3. CDC. Vital signs: HIV diagnosis, care, and treatment among persons living with HIV—United States, 2011. MMWR Morb Mortal Wkly Rep 2014;63:1113-7.

\section{Diagnoses and Prevalence of HIV Infection Among Hispanics or Latinos — United States, 2008-2013}

\author{
Kristen Mahle Gray, $\mathrm{MPH}^{1}$; Eduardo E Valverde, $\mathrm{DrPH}^{1}$; \\ Tian Tang, MS ${ }^{2}$; Azfar-e-Alam Siddiqi, MD, $\mathrm{PhD}^{1}$; H. Irene Hall, $\mathrm{PhD}^{1}$
}

Hispanics or Latinos* represent about $17 \%$ of the total U.S. population and are disproportionately affected by human immunodeficiency virus (HIV) infection in the United States $(1,2)$. In 2013, the rate of HIV diagnosis among Hispanics or Latinos (18.7) was nearly three times that of non-Hispanic

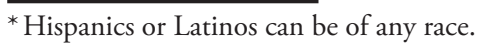

\section{INSIDE}

1104 CDC Grand Rounds: Understanding the Causes of Major Birth Defects - Steps to Prevention

1108 Establishment of an Ebola Treatment Unit and Laboratory — Bombali District, Sierra Leone, July 2014-January 2015

1112 Vital Signs: Improvements in Maternity Care Policies and Practices That Support Breastfeeding - United States, 2007-2013

1118 Update: Shortened Interval for Postvaccination Serologic Testing of Infants Born to Hepatitis B-Infected Mothers

1121 Notes from the Field: Severe Illness Associated with Reported Use of Synthetic Cannabinoids Mississippi, April 2015

1123 Notes from the Field: Measles in a Patient with Presumed Immunity — Los Angeles County, 2015

1124 Announcements

1125 QuickStats

Continuing Education examination available at http://www.cdc.gov/mmwr/cme/conted_info.html\#weekly.

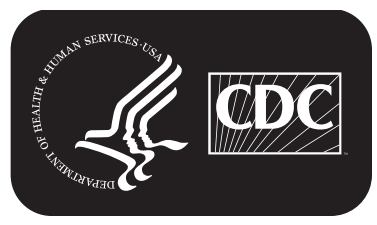

U.S. Department of Health and Human Services Centers for Disease Control and Prevention 
whites (6.6) (1). To better characterize HIV infection among Hispanics or Latinos aged $\geq 13$ years in the United States, CDC analyzed data from the National HIV Surveillance System (NHSS). During 2008-2013, the rate of diagnoses of HIV infection among adult and adolescent Hispanics or Latinos decreased from 28.3 per 100,000 population in 2008 to 24.3 in 2013 (estimated annual percentage change [EAPC] = -3.6); however, the number of diagnoses among males with infection attributed to male-to-male sexual contact increased $16 \%$, from 6,141 in 2008 to 7,098 in 2013 (EAPC = 3.0). In 2013, the rate of diagnosis of HIV infection among males (41.3) was six times the rate among females (6.8). During 2008-2013, behavioral risk factors for HIV infection among Hispanics or Latino differed among males and females and by place of birth. Among Hispanic or Latino males born in Puerto Rico, the proportion of HIV infections attributed to injection drug use $(24.9 \%)$ was greater than among those born elsewhere. Among HIV-infected Hispanic or Latino females, those born in the United States (21.2\%) and Puerto Rico (20.5\%) had a greater proportion of HIV infections attributed to injection drug use than those born elsewhere. Additional interventions and public health strategies to further decrease the rates of HIV among the Hispanic or Latino population are needed.

Data from NHSS reported to CDC from the early 1980s through December 2014 were used to determine the numbers and rates of diagnosis of HIV infection among Hispanics or Latinos aged $\geq 13$ years (adults and adolescents) during 2008-2013 and prevalence in 2012, by selected characteristics.
The numerator for each rate was the estimated number of diagnoses of HIV infection by diagnosis year. Appropriate subpopulations from the census or postcensus data from the U.S. Census Bureau were used for the denominator (2). Rates of infection by HIV transmission categories (male-to-male sexual contact, injection drug use, male-to-male sexual contact and injection drug use, heterosexual contact, or other) could not be calculated because the U.S. Census does not collect the data needed for the denominators. In calculating the EAPC in rates, populations were treated as actual populations and not samples, because the standard deviation of these populations was not available from the U.S. Census. Data from NHSS were also used to ascertain 1) HIV diagnoses in 2013 among Hispanics or Latinos by place of birth and transmission category, and 2) the numbers and rates of Hispanics or Latinos living with diagnosed HIV infection at year-end 2012 by area of residence at diagnosis. Birthplace information was available for $83.7 \%$ of Hispanics or Latinos in this analysis. Data were statistically adjusted for reporting delays and missing HIV transmission categories (3).

During 2008-2013, a total of 276,633 adults and adolescents received a diagnosis of HIV infection in the 50 states and the District of Columbia. Of these, 57,406 (20.8\%) were Hispanics or Latinos. A decline was observed in the rates of diagnosis per 100,000 population among Hispanic or Latino adults and adolescents, from 28.3 per 100,000 population in 2008 to 24.3 in 2013 (EAPC = -3.6) (Table 1). During 2008-2013, the HIV diagnosis rate decreased among Hispanic or Latino

The MMWR series of publications is published by the Center for Surveillance, Epidemiology, and Laboratory Services, Centers for Disease Control and Prevention (CDC), U.S. Department of Health and Human Services, Atlanta, GA 30329-4027.

Suggested citation: [Author names; first three, then et al., if more than six.] [Report title]. MMWR Morb Mortal Wkly Rep 2015;64:[inclusive page numbers].

\author{
Centers for Disease Control and Prevention \\ Thomas R. Frieden, MD, MPH, Director \\ Harold W. Jaffe, MD, MA, Associate Director for Science \\ Joanne Cono, MD, ScM, Director, Office of Science Quality \\ Chesley L. Richards, MD, MPH, Deputy Director for Public Health Scientific Services \\ Michael F. Iademarco, MD, MPH, Director, Center for Surveillance, Epidemiology, and Laboratory Services
}

MMWR Editorial and Production Staff (Weekly)

Sonja A. Rasmussen, MD, MS, Editor-in-Chief

Charlotte K. Kent, PhD, MPH, Executive Editor Jacqueline Gindler, MD, Editor

Teresa F. Rutledge, Managing Editor

Douglas W. Weatherwax, Lead Technical Writer-Editor

Soumya Dunworth, PhD, Teresa M. Hood, MS, Jude C. Rutledge, Writer-Editors
Martha F. Boyd, Lead Visual Information Specialist Maureen A. Leahy, Julia C. Martinroe,

Stephen R. Spriggs, Brian E. Wood, Moua Yang, Visual Information Specialists

Quang M. Doan, MBA, Phyllis H. King, Teresa C. Moreland, Terraye M. Starr, Information Technology Specialists
MMWR Editorial Board

Timothy F. Jones, MD, Chairman

Matthew L. Boulton, MD, MPH Virginia A. Caine, MD

Katherine Lyon Daniel, PhD

Jonathan E. Fielding, MD, MPH, MBA

David W. Fleming, MD
William E. Halperin, MD, DrPH, MPH

King K. Holmes, MD, PhD

Robin Ikeda, MD, MPH

Rima F. Khabbaz, MD

Phyllis Meadows, PhD, MSN, RN

Jewel Mullen, MD, MPH, MPA
Jeff Niederdeppe, $\mathrm{PhD}$

Patricia Quinlisk, MD, MPH

Patrick L. Remington, MD, MPH Carlos Roig, MS, MA

William L. Roper, MD, MPH

William Schaffner, MD 
TABLE 1. Diagnoses of HIV infection* among adult and adolescent Hispanics or Latinos, by selected characteristics — United States, 2008-2013

\begin{tabular}{|c|c|c|c|c|c|c|c|c|c|c|c|c|c|c|c|c|c|c|c|c|c|}
\hline \multirow[b]{2}{*}{ Characteristic } & \multicolumn{3}{|c|}{2008} & \multicolumn{3}{|c|}{2009} & \multicolumn{3}{|c|}{2010} & \multicolumn{3}{|c|}{2011} & \multicolumn{3}{|c|}{2012} & \multicolumn{3}{|c|}{2013} & \multirow[b]{2}{*}{ EAPC $\S$} & \multirow[b]{2}{*}{$\begin{array}{c}\mathrm{p}- \\
\text { value }\end{array}$} & \multirow[b]{2}{*}{$95 \% \mathrm{Cl}$} \\
\hline & No. & $\begin{array}{l}\text { Est. } \\
\text { no. }\end{array}$ & Rate & No. & $\begin{array}{l}\text { Est. } \\
\text { no. }{ }^{\dagger}\end{array}$ & Rate & No. & $\begin{array}{l}\text { Est. } \\
\text { no. }\end{array}$ & Rate & No. & $\begin{array}{l}\text { Est. } \\
\text { no. }{ }^{\dagger}\end{array}$ & Rate & No. & $\begin{array}{l}\text { Est. } \\
\text { no. }{ }^{\dagger}\end{array}$ & Rate & No. & $\begin{array}{l}\text { Est. } \\
\text { no. }\end{array}$ & Rate & & & \\
\hline \multicolumn{22}{|l|}{ Sex } \\
\hline Female & 1,656 & 1,686 & 10.1 & 1,588 & 1,623 & 9.5 & 1,429 & 1,479 & 7.9 & 1,297 & 1,362 & 7.1 & 1,180 & 1,266 & 6.4 & 1,227 & 1,370 & 6.8 & -9.6 & $<.0001$ & $(-11.1$ to -8.1$)$ \\
\hline Male & 7,967 & 8,106 & 45.0 & 7,773 & 7,949 & 42.8 & 7,565 & 7,819 & 40.6 & 7,566 & 7,914 & 40.0 & 7,743 & 8,264 & 40.8 & 7,748 & 8,568 & 41.3 & -2.0 & $<.0001$ & $(-2.7$ to -1.3$)$ \\
\hline \multicolumn{22}{|c|}{ Age group at diagnosis (yrs) } \\
\hline $13-24$ & 1,660 & 1,690 & 18.1 & 1,665 & 1,701 & 17.8 & 1,733 & 1,789 & 16.8 & 1,717 & 1,794 & 16.6 & 1,843 & 1,963 & 17.9 & 1,729 & 1,901 & 17.0 & -1.0 & 0.16 & (-2.4 to 0.4$)$ \\
\hline $25-34$ & 3,243 & 3,300 & 41.0 & 3,151 & 3,224 & 39.4 & 3,027 & 3,129 & 37.0 & 2,978 & 3,115 & 36.4 & 3,106 & 3,315 & 38.3 & 3,171 & 3,514 & 40.1 & -1.1 & 0.052 & (-2.1 to 0.0$)$ \\
\hline $35-44$ & 2,686 & 2,732 & 39.6 & 2,597 & 2,655 & 37.6 & 2,340 & 2,419 & 33.0 & 2,234 & 2,341 & 31.3 & 2,071 & 2,213 & 28.9 & 2,074 & 2,295 & 29.5 & -6.8 & $<.0001$ & $(-8.0$ to -5.6$)$ \\
\hline $45-54$ & 1,495 & 1,521 & 30.9 & 1,355 & 1,385 & 26.8 & 1,322 & 1,368 & 24.8 & 1,373 & 1,438 & 25.2 & 1,333 & 1,424 & 24.2 & 1,382 & 1,535 & 25.2 & -4.2 & $<.0001$ & $(-5.8$ to -2.7$)$ \\
\hline $55-64$ & 417 & 425 & 15.1 & 442 & 453 & 15.1 & 451 & 466 & 14.3 & 423 & 441 & 12.8 & 432 & 465 & 12.8 & 494 & 551 & 14.4 & -2.7 & 0.061 & $(-5.5$ to 0.1$)$ \\
\hline$\geq 65$ & 122 & 125 & 4.8 & 151 & 154 & 5.6 & 121 & 126 & 4.5 & 138 & 147 & 4.9 & 138 & 149 & 4.7 & 125 & 141 & 4.2 & -2.7 & 0.308 & (-7.6 to 2.5 ) \\
\hline \multicolumn{22}{|c|}{ Transmission category } \\
\hline \multicolumn{22}{|c|}{ Male adult and adolescent } \\
\hline $\begin{array}{l}\text { Male-to-male } \\
\text { sexual } \\
\text { contact }\end{array}$ & 4,929 & 6,141 & - & 4,924 & 6,172 & - & 5,046 & 6,233 & - & 5,224 & 6,405 & - & 5,452 & 6,874 & - & 5,410 & 7,098 & - & 3.0 & $<.0001$ & (2.2 to 4.0$)$ \\
\hline $\begin{array}{l}\text { Injection drug } \\
\text { use }\end{array}$ & 449 & 674 & - & 367 & 584 & - & 322 & 529 & - & 291 & 478 & - & 237 & 436 & - & 238 & 452 & - & -8.6 & $<.001$ & $(-12.8$ to -4.2$)$ \\
\hline $\begin{array}{l}\text { Male-to-male } \\
\text { sexual } \\
\text { contact and } \\
\text { injection } \\
\text { drug use }\end{array}$ & 330 & 408 & - & 272 & 351 & - & 253 & 329 & - & 228 & 301 & - & 240 & 320 & - & 199 & 278 & - & -6.6 & $<.01$ & $(-11.1$ to -1.9$)$ \\
\hline $\begin{array}{l}\text { Heterosexual } \\
\text { contact }\end{array}$ & 677 & 872 & - & 640 & 833 & - & 556 & 722 & - & 551 & 724 & - & 459 & 624 & - & 518 & 731 & - & -5.2 & $<.01$ & $(-8.3$ to -2.0$)$ \\
\hline Other ${ }^{* *}$ & 1,582 & 11 & - & 1,570 & 9 & - & 1,388 & 6 & - & 1,272 & 7 & - & 1,355 & 9 & - & 1,383 & 10 & - & -1.5 & 0.94 & $(-34.4$ to 47.7$)$ \\
\hline \multicolumn{22}{|c|}{ Female adult and adolescent } \\
\hline $\begin{array}{l}\text { Injection drug } \\
\text { use }\end{array}$ & 191 & 297 & - & 164 & 275 & - & 96 & 191 & - & 100 & 194 & - & 97 & 180 & - & 78 & 167 & - & -11.8 & $<.01$ & $(-18.2$ to -4.9$)$ \\
\hline $\begin{array}{l}\text { Heterosexual } \\
\text { contact }^{\Uparrow}\end{array}$ & 883 & 1,384 & - & 820 & 1,342 & - & 762 & 1,283 & - & 635 & 1,162 & - & 577 & 1,076 & - & 580 & 1,194 & - & -4.5 & $<.0001$ & $(-6.4$ to -2.4$)$ \\
\hline Other** & 582 & 5 & - & 604 & 6 & - & 571 & 4 & - & 562 & 6 & - & 506 & 9 & - & 569 & 9 & - & 13.9 & 0.532 & (-24.3 to 71.4$)$ \\
\hline \multicolumn{22}{|c|}{ Area of residence $^{t \dagger}$} \\
\hline Urban & 8,546 & 8,697 & 31.2 & 8,332 & 8,520 & 29.7 & 7,997 & 8,267 & 27.2 & 7,815 & 8,177 & 26.3 & 7,945 & 8,480 & 26.6 & 7,913 & 8,759 & 26.8 & -3.5 & $<.0001$ & $(-4.2$ to -2.9$)$ \\
\hline Suburban & 776 & 789 & 17.5 & 713 & 728 & 15.7 & 681 & 703 & 13.7 & 714 & 748 & 14.1 & 666 & 708 & 13.0 & 699 & 770 & 13.8 & -5.3 & $<.0001$ & $(-7.4$ to -3.2$)$ \\
\hline Rural & 270 & 273 & 12.0 & 281 & 286 & 12.2 & 287 & 295 & 11.7 & 297 & 308 & 11.9 & 273 & 291 & 11.0 & 335 & 368 & 13.6 & 0.5 & 0.754 & $(-2.8$ to 4.0$)$ \\
\hline Unknown & 31 & 33 & - & 35 & 38 & - & 29 & 33 & - & 37 & 44 & - & 39 & 50 & - & 28 & 41 & - & - & - & - \\
\hline Total ${ }^{\S}$ & 9,623 & 9,792 & 28.3 & 9,361 & 9,573 & 26.8 & 8,994 & 9,298 & 24.4 & 8,863 & 9,276 & 23.8 & 8,923 & 9,529 & 23.9 & 8,975 & 9,938 & 24.3 & -3.6 & $<.0001$ & $(-4.2$ to -3.0$)$ \\
\hline
\end{tabular}

Abbreviations: $\mathrm{Cl}$ = confidence interval; EAPC = estimated annual percentage change; Est. = estimated; HIV = human immunodeficiency virus.

* Data include persons with a diagnosis of HIV infection regardless of stage of disease at diagnosis.

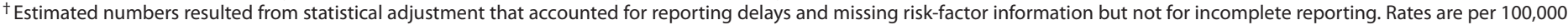
population. Rates are not calculated by transmission category because of the lack of denominator data.

$\S$ EAPC is based on rates with the exception of transmission category, which is based on the estimated number of diagnoses.

"Heterosexual contact with a person known to have, or to be at high risk for, HIV infection.

** Includes hemophilia, blood transfusion, perinatal exposure, and risk factor not reported or not identified.

${ }^{+\dagger}$ Urban: population of $\geq 500,000$. Suburban: population of 50,000-499,999. Rural: nonmetropolitan area.

$\S \S$ Because column totals for estimated numbers were calculated independently of the values for the subpopulations, the values in each column might not sum to the column total.

males from 45.0 per 100,000 to $41.3(\mathrm{EAPC}=-2.0)$ and among females from 10.1 per 100,000 to $6.8($ EAPC $=-9.6)$. The rates remained stable or decreased among all age groups, with the largest decline among persons aged 35-44 years (39.6 per 100,000 to 29.5 [EAPC = -6.8]). Among Hispanic or Latino males with infection attributed to male-to-male sexual contact, the number of HIV diagnoses increased $16 \%$ $(\mathrm{EAPC}=3.0)$, whereas diagnoses decreased in other transmission categories (Figure). Among Hispanic or Latino females, the estimated number of HIV diagnoses decreased in persons with infection attributed to injection drug use or heterosexual contact. The largest declines in males $(\mathrm{EAPC}=-8.6)$ and females $(\mathrm{EAPC}=-11.8)$ were observed among those with infection attributed to injection drug use (Table 1).
In 2013, the HIV diagnosis rate per 100,000 population among males (41.3) was more than six times the rate among females (6.8). By age group, the highest rate of HIV diagnosis (40.1) among Hispanics or Latinos occurred among persons aged 25-34 years. By transmission category, the largest number of HIV diagnoses occurred among males with infection attributed to male-to-male sexual contact (7,098 [82.8\%]), and among females with infection attributed to heterosexual contact $(1,194$ [87.2\%]) (Table 1$)$. The estimated rate of diagnosis for 2013 ranged from 2.3 in Idaho to 90.1 in the District of Columbia (Table 2).

HIV transmission category among Hispanics or Latinos varied by place of birth (Table 3 ). Infection attributed to maleto-male sexual contact accounted for the majority of infection 
FIGURE. Estimated number of diagnoses attributed to male-to-male sexual contact* compared with other transmission categories among Hispanic or Latino males aged $\geq 13$ years, by year - United States, 2008-2013

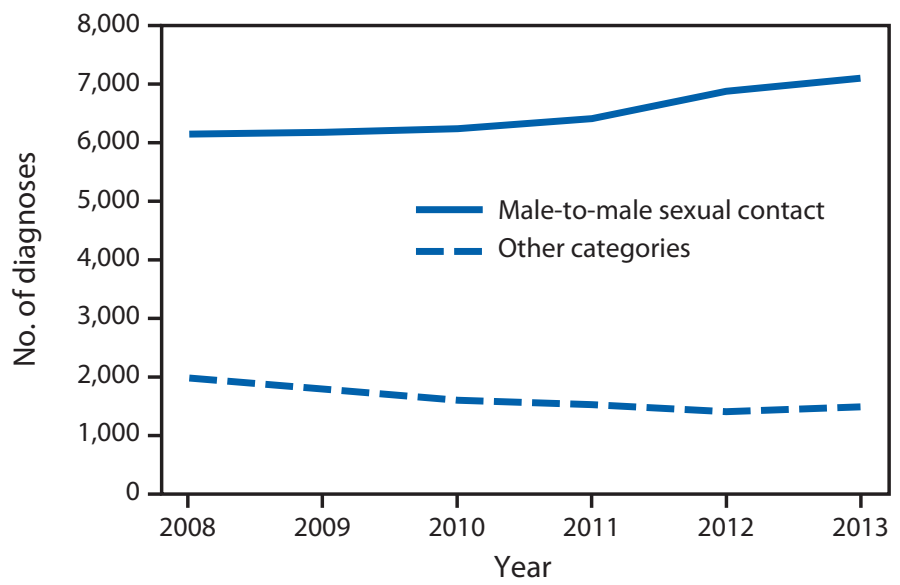

* Male-to-male sexual contact does not include male-to-male sexual contact and injection drug use combined.

transmissions among males, irrespective of place of birth, ranging from a low of 53.6\% among persons born in Puerto Rico to a high of $86.4 \%$ among persons born in South America. Hispanic or Latino males born in Puerto Rico had a higher proportion of HIV infections attributed to injection drug use $(24.9 \%)$ than those born elsewhere, whereas Hispanic or Latino females born in the United States $(21.2 \%)$ and Puerto Rico $(20.5 \%)$ had a higher proportion of HIV infections attributed to injection drug use than those born elsewhere. A smaller proportion of Hispanic or Latino males born in the United States $(6.6 \%)$ had infection attributed to heterosexual contact compared with male Hispanics or Latinos born elsewhere. A smaller proportion of Hispanic or Latino females born in the United States (78.2\%) and Puerto Rico (79.2\%) had infection attributed to heterosexual contact compared with female Hispanics or Latinos born elsewhere.

At year-end 2012, an estimated 911,602 adults and adolescents were living with diagnosed HIV infection, and of these, 183,300 (20.1\%) were Hispanics or Latinos (Table 2); the rate of persons living with HIV infection among Hispanics or Latinos was estimated at 458.8 per 100,000 population, and the estimated HIV prevalence ranged from 73.6 per 100,000 population in Montana to 1,947.5 in the District of Columbia (Table 2).

\section{Discussion}

During 2008-2013, overall diagnoses of HIV infection among adult and adolescent Hispanics or Latinos decreased in the United States. However, decreases have not occurred uniformly because diagnoses of HIV infection among men who have sex with men increased. This increase might have resulted from increased incidence of HIV infection, an increase

\section{Summary}

What is already known on this topic?

Hispanics or Latinos represent about $17 \%$ of the total U.S. population and are disproportionately affected by human immunodeficiency virus (HIV) infection in the United States. In 2013, the rate of HIV diagnosis among Hispanics or Latinos (18.7 per 100,000) was nearly three times that of non-Hispanic whites (6.6).

What is added by this report?

During 2008-2013, the overall rate of the diagnoses of HIV infection among adult and adolescent Hispanics or Latinos decreased (from 28.3 per 100,000 in 2008 to 24.3 in 2013; estimated annual percentage change [EAPC] = -3.6); however, diagnoses of HIV infection among males with infection attributed to male-to-male sexual contact increased (EAPC $=3.0)$.

What are the implications for public health practice?

The higher rate of HIV infection among Hispanics or Latinos indicates that much work still needs to be done to reach Hispanics or Latinos at high risk for acquiring or transmitting HIV infection. Targeted strategies for Hispanic or Latino subpopulations, such as men who have sex with men and persons who inject drugs, present prevention challenges and warrant expanded efforts.

in HIV testing among Hispanic or Latino men who have sex with men, or a combination of both of these factors (4).

An estimated $43 \%$ of Hispanics or Latinos who received an HIV diagnosis were not born in the United States or Puerto Rico (a U.S. territory), and among these Hispanic or Latino immigrants, $66 \%$ were men who have sex with men. The large proportion of HIV diagnoses in the United States among Hispanics or Latinos who are immigrants is important to consider when developing HIV prevention interventions, given that approximately $40 \%$ of Hispanic or Latino immigrants do not speak English well or at all (5) and because certain socioeconomic factors, such as limited access to health care, lack of health insurance, and poverty, might be at play ( $($ ).

Findings from this report also confirm earlier findings that Hispanics or Latinos are not a homogenous group, and risk factors differ by place of birth $(7,8)$. The majority of males born in Puerto Rico with infection diagnosed during 2008-2013 had infections attributed to male-to-male sexual contact, highlighting a change in HIV transmission patterns, which until recently indicated that the most common HIV transmission category among men in Puerto Rico was injection drug use (9). Still, a much larger proportion of Hispanic or Latino males born in Puerto Rico reported infection attributed to injection drug use compared with Hispanic or Latino males born elsewhere. HIV care providers working in communities where Puerto Ricans reside should be mindful of a recent report indicating that levels 
TABLE 2. Diagnoses of HIV infection* in 2013, and persons living with diagnosed HIV infection at year-end 2012, among adult and adolescent Hispanics or Latinos, by area of residence - United States

\begin{tabular}{|c|c|c|c|c|c|c|}
\hline \multirow[b]{2}{*}{ Area of residence } & \multicolumn{3}{|c|}{ Diagnoses of HIV infection, 2013} & \multicolumn{3}{|c|}{ Living with HIV infection, year-end 2012} \\
\hline & No. & Est. no. ${ }^{\dagger}$ & Rate & No. & Est. no. ${ }^{\dagger}$ & Rate \\
\hline Alabama & 14 & 15 & 10.6 & 317 & 315 & 231.9 \\
\hline Alaska & 2 & 2 & 6.2 & 65 & 66 & 196.4 \\
\hline Arizona & 252 & 259 & 17.3 & 3,719 & 3,714 & 254.7 \\
\hline Arkansas & 19 & 24 & 16.5 & 281 & 288 & 208.0 \\
\hline California & 1,947 & 2,198 & 19.5 & 38,917 & 39,623 & 358.3 \\
\hline Colorado & 96 & 98 & 12.0 & 2,282 & 2,279 & 284.8 \\
\hline Connecticut & 92 & 103 & 25.7 & 3,333 & 3,373 & 865.3 \\
\hline Delaware & 9 & 10 & 17.1 & 232 & 235 & 414.8 \\
\hline District of Columbia & 42 & 47 & 90.1 & 967 & 989 & $1,947.5$ \\
\hline Florida & 1,266 & 1,299 & 34.4 & 20,518 & 20,478 & 559.8 \\
\hline Georgia & 160 & 249 & 38.2 & 2,323 & 2,423 & 377.8 \\
\hline Hawaii & 13 & 14 & 14.7 & 227 & 230 & 244.4 \\
\hline Idaho & 3 & 3 & 2.3 & 113 & 113 & 87.6 \\
\hline Illinois & 345 & 405 & 25.6 & 5,829 & 5,997 & 385.7 \\
\hline Indiana & 49 & 51 & 17.0 & 730 & 731 & 253.5 \\
\hline lowa & 9 & 9 & 7.8 & 181 & 181 & 161.0 \\
\hline Kansas & 30 & 32 & 14.0 & 427 & 427 & 193.8 \\
\hline Kentucky & 19 & 19 & 19.1 & 328 & 328 & 333.2 \\
\hline Louisiana & 62 & 64 & 38.1 & 777 & 774 & 478.1 \\
\hline Maine & 2 & 2 & 15.6 & 57 & 58 & 427.3 \\
\hline Maryland & 79 & 103 & 25.7 & 1,548 & 1,609 & 417.1 \\
\hline Massachusetts & 203 & 297 & 55.5 & 4,397 & 4,623 & 895.9 \\
\hline Michigan & 38 & 39 & 11.7 & 711 & 709 & 217.7 \\
\hline Minnesota & 29 & 30 & 15.9 & 664 & 663 & 363.4 \\
\hline Mississippi & 13 & 13 & 20.5 & 230 & 229 & 364.7 \\
\hline Missouri & 19 & 19 & 11.7 & 615 & 614 & 381.4 \\
\hline Montana & 1 & 1 & 4.2 & 17 & 17 & 73.6 \\
\hline Nebraska & 14 & 14 & 11.1 & 246 & 246 & 199.2 \\
\hline Nevada & 139 & 143 & 25.0 & 1,643 & 1,640 & 295.3 \\
\hline New Hampshire & 3 & 3 & 10.8 & 148 & 149 & 500.8 \\
\hline New Jersey & 395 & 469 & 35.6 & 9,405 & 9,587 & 745.5 \\
\hline New Mexico & 80 & 82 & 10.7 & 1,244 & 1,242 & 163.8 \\
\hline New York & 1,178 & 1,277 & 44.5 & 42,838 & 42,844 & $1,518.0$ \\
\hline North Carolina & 124 & 127 & 20.9 & 1,728 & 1,728 & 293.1 \\
\hline North Dakota & 2 & 2 & 14.0 & 10 & 10 & 81.3 \\
\hline Ohio & 60 & 62 & 22.1 & 997 & 996 & 369.2 \\
\hline Oklahoma & 24 & 30 & 11.5 & 478 & 490 & 198.6 \\
\hline Oregon & 46 & 51 & 14.8 & 691 & 705 & 210.1 \\
\hline Pennsylvania & 179 & 185 & 31.0 & 4,929 & 4,902 & 850.0 \\
\hline Rhode Island & 19 & 21 & 19.6 & 537 & 548 & 524.8 \\
\hline South Carolina & 40 & 41 & 22.5 & 577 & 576 & 321.9 \\
\hline South Dakota & 4 & 4 & 20.5 & 18 & 18 & 99.5 \\
\hline Tennessee & 39 & 40 & 18.2 & 658 & 658 & 302.9 \\
\hline Texas & 1,582 & 1,738 & 22.9 & 21,201 & 21,617 & 291.7 \\
\hline Utah & 19 & 19 & 7.1 & 480 & 479 & 181.1 \\
\hline Vermont & 1 & 1 & 13.5 & 24 & 24 & 304.1 \\
\hline Virginia & 90 & 93 & 17.3 & 1,630 & 1,599 & 308.9 \\
\hline Washington & 78 & 80 & 13.5 & 1,398 & 1,397 & 245.3 \\
\hline West Virginia & 6 & 7 & 34.3 & 57 & 58 & 309.8 \\
\hline Wisconsin & 38 & 39 & 15.4 & 663 & 662 & 268.5 \\
\hline Wyoming & 2 & 2 & 4.9 & 38 & 38 & 94.1 \\
\hline Total $^{\S}$ & 8,975 & 9,938 & 24.3 & 181,443 & 183,300 & 458.8 \\
\hline
\end{tabular}

Abbreviation: HIV = human immunodeficiency virus.

* Data include persons with a diagnosis of HIV infection regardless of stage of disease at diagnosis.

† Estimated numbers resulted from statistical adjustment that accounted for reporting delays but not for incomplete reporting. Rates are per 100,000 population.

$\S$ Because column totals for estimated numbers were calculated independently of the values for the subpopulations, the values in each column might not sum to the column total. 
Morbidity and Mortality Weekly Report

TABLE 3. Diagnoses of HIV infection* among adult and adolescent Hispanics or Latinos, by transmission category and place of birth United States, 2008-2013

\begin{tabular}{|c|c|c|c|c|c|c|c|c|c|c|c|c|c|c|c|}
\hline \multirow[b]{2}{*}{ Characteristic } & \multicolumn{3}{|c|}{ Central America } & \multicolumn{3}{|c|}{ Cuba } & \multicolumn{3}{|c|}{ Mexico } & \multicolumn{3}{|c|}{ Puerto Rico } & \multicolumn{3}{|c|}{ South America } \\
\hline & No. & Est. no. ${ }^{\S}$ & $\%$ & No. & Est. no.§ & $\%$ & No. & Est. no. $§$ & $\%$ & No. & Est. no. ${ }^{\S}$ & $\%$ & No. & Est. no. ${ }^{\S}$ & $\%$ \\
\hline \multicolumn{16}{|l|}{ Transmission category } \\
\hline \multicolumn{16}{|l|}{ Male adult and adolescent } \\
\hline $\begin{array}{l}\text { Male-to-male sexual } \\
\text { contact }\end{array}$ & 1,835 & 2,604 & 74.6 & 1,169 & 1,242 & 82.4 & 5,466 & 6,997 & 80.2 & 812 & 978 & 53.6 & 1,859 & 2,070 & 86.4 \\
\hline Injection drug use & 64 & 158 & 4.5 & 27 & 38 & 2.5 & 261 & 411 & 4.7 & 380 & 456 & 24.9 & 19 & 51 & 2.1 \\
\hline $\begin{array}{l}\text { Male-to-male sexual } \\
\text { contact and injection } \\
\text { drug use }\end{array}$ & 61 & 99 & 2.8 & 25 & 28 & 1.9 & 233 & 323 & 3.7 & 83 & 93 & 5.1 & 39 & 47 & 2.0 \\
\hline Heterosexual contact** & 451 & 625 & 17.9 & 166 & 197 & 13.1 & 673 & 984 & 11.3 & 215 & 295 & 16.1 & 164 & 225 & 9.4 \\
\hline Other ${ }^{\dagger \dagger}$ & 921 & 5 & 0.1 & 95 & 2 & 0.1 & 1,701 & 7 & 0.1 & 248 & 4 & 0.2 & 224 & 1 & 0.0 \\
\hline Subtotal & 3,332 & 3,491 & 100.0 & 1,482 & 1,507 & 100.0 & 8,334 & 8,722 & 100.0 & 1,738 & 1,826 & 100.0 & 2,305 & 2,395 & 100.0 \\
\hline \multicolumn{16}{|c|}{ Female adult or adolescent } \\
\hline Injection drug use & 14 & 55 & 6.2 & 4 & 6 & 5.3 & 33 & 65 & 5.8 & 99 & 128 & 20.5 & 10 & 22 & 7.0 \\
\hline Heterosexual contact co* $^{* *}$ & 435 & 828 & 93.5 & 82 & 109 & 93.5 & 631 & 1,051 & 93.9 & 300 & 495 & 79.2 & 184 & 286 & 92.3 \\
\hline Other ${ }^{\dagger \dagger}$ & 394 & 3 & 0.4 & 29 & 1 & 1.1 & 405 & 3 & 0.3 & 191 & 2 & 0.3 & 103 & 2 & 0.7 \\
\hline Subtotal & 843 & 886 & 100.0 & 115 & 117 & 100.0 & 1,069 & 1,119 & 100.0 & 590 & 624 & 100.0 & 297 & 310 & 100.0 \\
\hline Total§§ & 4,175 & 4,377 & 100.0 & 1,597 & 1,624 & 100.0 & 9,403 & 9,840 & 100.0 & 2,328 & 2,450 & 100.0 & 2,602 & 2,704 & 100.0 \\
\hline
\end{tabular}

See table footnotes on next page.

of linkage to care, retention in care, prescription of antiretroviral therapy, and viral suppression were lower among Hispanics or Latinos with HIV infection attributed to injection drug use than among those with infection attributed to male-to-male sexual contact and heterosexual contact (10).

The findings in this report are subject to at least two limitations. First, misclassification of Hispanics or Latinos as members of other races/ethnicities might have resulted in underestimation of the number of Hispanics or Latinos overall and of Hispanic or Latino subgroups. Second, birthplace information was missing for $16 \%$ of Hispanics or Latinos in this analysis. Depending on the distribution of birthplaces for persons with missing information, transmission category prevalence for certain subgroups might have been larger or smaller.

The disproportionate rate of HIV infection among Hispanics or Latinos and the disparities found within this population indicate that much work still needs to be done to reach Hispanics or Latinos at high risk for acquiring or transmitting HIV infection. $\mathrm{CDC}$ and its partners are pursuing a high-impact prevention approach to maximize the effectiveness of current HIV prevention methods. Example activities include providing technical assistance to health departments and community-based organizations to deliver effective prevention interventions to Hispanics or Latinos, and supporting testing projects and campaigns that focus on Hispanics or Latinos, such as Reasons, which encourages HIV testing among Hispanic or Latino men who have sex with men. CDC funds health departments across the United States and its territories for core HIV prevention activities, including activities for Hispanics or Latinos, and supports projects to optimize care outcomes, such as the Care and Prevention in the United States demonstration project, which promotes increased testing and linkage to, retention in, and reengagement in care for racial and ethnic minorities living with HIV (๑).

\footnotetext{
${ }^{1}$ Division of HIV/AIDS Prevention, National Center for HIV/AIDS, Viral Hepatitis, STD, and TB Prevention, CDC; ${ }^{2}$ ICF International, Atlanta, Georgia.
}

Corresponding author: Kristen Mahle Gray, kgray1@cdc.gov, 404-639-2050.

\section{References}

1. CDC. Diagnoses of HIV infection in the United States and dependent areas, 2013. HIV Surveillance Report 2015(25). Available at http:// www.cdc.gov/hiv/library/reports/surveillance/2013/surveillance_report_ vol_25.html.

2. US Census Bureau. Population estimates. Available at http://www.census. gov/popest/data.

3. Harrison KM, Kajese T, Hall HI, Song R. Risk factor redistribution of the national HIV/AIDS surveillance data: an alternative approach. Public Health Rep 2008;123:618-27.

4. Johnson AS, Hall HI, Hu X, Lansky A, Holtgrave DR, Mermin J. Trends in diagnoses of HIV infection in the United States, 2002-2011. JAMA 2014;312:432-4.

5. US Census Bureau. American Community Survey, 2012. Englishspeaking ability of the foreign-born population in the United States. Available at https://www.census.gov/content/dam/Census/library/ publications/2014/acs/acs-26.pdf.

6. CDC. HIV among Latinos. Available at http://www.cdc.gov/hiv/group/ racialethnic/hispaniclatinos/index.html.

7. CDC. HIV/AIDS among Hispanics-United States, 2001-2005. MMWR Morb Mortal Wkly Rep 2007;56:1052-7.

8. Espinoza L, Hall HI, Hu X. Diagnoses of HIV infection among Hispanics/Latinos in 40 states and Puerto Rico, 2006-2009. J Acquir Immune Defic Syndr 2012;60:205-13.

9. CDC. Incidence and diagnoses of HIV infection-Puerto Rico, 2006. MMWR Morb Mortal Wkly Rep 2009;58:589-91.

10. CDC. Hispanics or Latinos living with diagnosed HIV: progress along the continuum of HIV care-United States, 2010. MMWR Morb Mortal Wkly Rep 2014;63:886-90. 
TABLE 3. (Continued) Diagnoses of HIV infection* among adult and adolescent Hispanics or Latinos, by transmission category and place of birth - United States, 2008-2013

\begin{tabular}{|c|c|c|c|c|c|c|c|c|c|c|c|c|}
\hline \multirow[b]{2}{*}{ Characteristic } & \multicolumn{3}{|c|}{ United States } & \multicolumn{3}{|c|}{ Other $^{\dagger}$} & \multicolumn{3}{|c|}{ Unknown" } & \multicolumn{3}{|c|}{ Total } \\
\hline & No. & Est. no. ${ }^{\S}$ & $\%$ & No. & Est. no. ${ }^{\S}$ & $\%$ & No. & Est. no. ${ }^{\S}$ & $\%$ & No. & Est. no. ${ }^{\text {ฐी }}$ & $\%$ \\
\hline \multicolumn{13}{|l|}{ Transmission category } \\
\hline \multicolumn{13}{|l|}{ Male adult and adolescent } \\
\hline $\begin{array}{l}\text { Male-to-male sexual } \\
\text { contact }\end{array}$ & 14,623 & 17,345 & 81.6 & 748 & 977 & 70.8 & 4,473 & 6,709 & 83.5 & 30,985 & 38,923 & 80.1 \\
\hline Injection drug use & 905 & 1,404 & 6.6 & 28 & 95 & 6.9 & 220 & 541 & 6.7 & 1,904 & 3,154 & 6.5 \\
\hline $\begin{array}{l}\text { Male-to-male sexual } \\
\text { contact and injection } \\
\text { drug use }\end{array}$ & 887 & 1,089 & 5.1 & 37 & 48 & 3.5 & 157 & 260 & 3.2 & 1,522 & 1,987 & 4.1 \\
\hline Heterosexual contact ${ }^{* *}$ & 1,189 & 1,402 & 6.6 & 167 & 258 & 18.7 & 376 & 520 & 6.5 & 3,401 & 4,506 & 9.3 \\
\hline Other ${ }^{\dagger \dagger}$ & 2,668 & 26 & 0.1 & 341 & 2 & 0.2 & 2,352 & 5 & 0.1 & 8,550 & 52 & 0.1 \\
\hline \multicolumn{9}{|l|}{ Female adult or adolescent } & 100.0 & 46,362 & 48,620 & 100.0 \\
\hline Injection drug use & 497 & 795 & 21.2 & 11 & 40 & 6.2 & 58 & 194 & 14.6 & 726 & 1,305 & 14.8 \\
\hline Heterosexual contact** & 1,850 & 2,938 & 78.2 & 314 & 598 & 93.6 & 461 & 1,137 & 85.2 & 4,257 & 7,442 & 84.7 \\
\hline Other ${ }^{\dagger \dagger}$ & 1,253 & 23 & 0.6 & 282 & 1 & 0.1 & 737 & 3 & 0.3 & 3,394 & 39 & 0.4 \\
\hline Subtotal & 3,600 & 3,757 & 100.0 & 607 & 639 & 100.0 & 1,256 & 1,334 & 100.0 & 8,377 & 8,786 & 100.0 \\
\hline Total $\$ \S$ & 23,872 & 25,022 & 100.0 & 1,928 & 2,019 & 100.0 & 8,834 & 9,369 & 100.0 & 54,739 & 57,406 & 100.0 \\
\hline
\end{tabular}

Abbreviations: Est. = estimated; HIV = human immunodeficiency virus.

* Data include persons with a diagnosis of HIV infection regardless of stage of disease at diagnosis.

† Places of birth other than those specified.

$\S$ Estimated numbers resulted from statistical adjustment that accounted for reporting delays and missing risk-factor information but not for incomplete reporting.

" Entries include persons whose place of birth is not among those listed and persons whose place of birth is unknown.

** Heterosexual contact with a person known to have, or to be at high risk for, HIV infection.

${ }^{+\dagger}$ Includes hemophilia, blood transfusion, perinatal exposure, and risk factor not reported or not identified.

$\S \S$ Because column totals for estimated numbers were calculated independently of the values for the subpopulations, the values in each column might not sum to the column total. 


\title{
CDC Grand Rounds: Understanding the Causes of Major Birth Defects - Steps to Prevention
}

\author{
Regina M. Simeone, $\mathrm{MPH}^{1}$; Marcia L. Feldkamp, $\mathrm{PhD}^{2}$; Jennita Reefhuis, $\mathrm{PhD}^{1}$; Allen A. Mitchell, $\mathrm{MD}^{3}$; Suzanne M. Gilboa, PhD ${ }^{1}$; \\ Margaret A. Honein, $\mathrm{PhD}^{1}$; John Iskander, $\mathrm{MD}^{4}$
}

Major birth defects (birth defects) are defined as structural abnormalities, present at birth, with surgical, medical, or cosmetic importance. Each year in the United States, 3\% of live births (approximately 120,000 infants) have an identifiable structural birth defect (1). Examples of birth defects include neural tube defects, such as spina bifida; orofacial clefts; abdominal wall defects, such as gastroschisis; and congenital heart defects, such as hypoplastic left heart syndrome. Collectively, congenital heart defects are the most common birth defects $(27 \%)$, followed by musculoskeletal defects (18\%), genitourinary defects $(15 \%)$, orofacial defects $(5 \%)$, and neural tube defects (2\%) (2).

\section{Public Health Burden}

Birth defects are associated with high health care resource use, morbidity, and mortality, and are a leading cause of infant mortality in the United States, resulting in 1.2 deaths per 1,000 live births (3). Advances in medical care and technology have improved survival among children with major birth defects; however, those who survive infancy might face physical or mental limitations, or poor health as a consequence of their birth defect. Birth defects are also costly. In 2004, hospitalizations of patients with birth defects as the principal diagnosis accounted for $\$ 2.6$ billion in hospital costs. The most common types of birth defects were cardiac and circulatory anomalies (33.5\% of hospitalizations), followed by digestive tract anomalies (18.5\% of hospitalizations) (4). For newborns with certain birth defects, hospital charges might be four to eight times higher than charges for newborns with uncomplicated births (5). Additional medical costs, costs associated with lost earnings, and issues surrounding quality of life can further increase the extent to which families and persons are affected by birth defects.

This is another in a series of occasional MMWR reports titled CDC Grand Rounds. These reports are based on grand rounds presentations at CDC on high-profile issues in public health science, practice, and policy. Information about CDC Grand Rounds is available at http://www.cdc.gov/about/grand-rounds.

\section{Challenges in Studying Risk Factors for Birth Defects}

Most birth defects develop during the first trimester of pregnancy, often before a woman knows she is pregnant. For this reason, pregnancy planning and obtaining prenatal care are key factors in preventing birth defects. Human teratogens (agents known to cause birth defects) include certain medications, such as thalidomide (used in patients with leprosy), isotretinoin (used to treat severe acne), valproic acid (used to treat seizures), methotrexate (used to treat psoriasis, rheumatoid arthritis, and cancer), and mycophenolate mofetil (used in transplant recipients) used during pregnancy; maternal infections, such as rubella and varicella during pregnancy; maternal conditions, such as poorly controlled pregestational diabetes; and smoking or alcohol use during early pregnancy (G). Suspected risk factors include maternal prepregnancy obesity; use of opioid pain medications, trimethoprimsulfamethoxazole (an antibiotic), and selective serotonin reuptake inhibitors (a class of anti-depressant medication); and certain occupational exposures.* Although the evidence regarding known and suspected risk factors for birth defects continues to grow, the causes of the majority of birth defects remain unknown.

Achieving the ultimate goal of preventing birth defects will require identifying modifiable causes. However, studying risk factors presents a number of challenges. Because individual birth defects are rare, cohort studies, pregnancy registry studies, and data-linkage studies might be too small or costly, might lack specific exposure and outcome data, or might not be populationbased. For these reasons, case-control studies are commonly used to study specific birth defects. Because most birth defects develop during the first 8 weeks of embryogenesis, modifiable exposures that occur early in pregnancy need to be identified. However, it might be difficult to accurately capture information on maternal exposures and the time in pregnancy in which they occurred, since case-control studies typically rely on maternal reports, which can be subject to recall bias. Nevertheless, if mothers of case and control infants are interviewed systematically using the same protocol, opportunities for recall bias are reduced. Other challenges include ascertaining all birth defects, including those among induced abortions and stillbirths, accurately classifying different birth defects, and identifying appropriate control groups. *Additional information available at http://www.cdc.gov/ncbddd/birthdefects/
nbdps.html. 


\section{Birth Defects Studies}

National Birth Defects Prevention Study. The National Birth Defects Prevention Study (NBDPS) was initiated in 1996 and is a population-based case-control study that was conducted in 10 study centers in the United States that collected data on births with estimated dates of delivery from October 1997 through December 2011. Case infants were live born, stillborn, or terminations with major structural birth defects identified from active birth defects surveillance systems; control infants were those without major birth defects, selected from live born infants in the same regions ( 7 ). Mothers were contacted approximately 6 weeks to 24 months after the estimated date of delivery for their pregnancy and completed a computer-assisted telephone interview that asked detailed questions about potential risk factors throughout pregnancy, including diet, medication use, and exposure to environmental factors (7). Approximately 44,000 women were interviewed for the NBDPS. There have been approximately 240 peerreviewed NBDPS publications to date, and additional analyses are ongoing. NBDPS data have been important in furthering understanding of the association between pregestational diabetes and congenital heart defects (odds ratio $[\mathrm{OR}]=4.6$, $95 \%$ confidence interval $[\mathrm{CI}]=2.9-7.5)(8)$ and in identifying potentially important associations between opioid medication use and congenital heart defects $(\mathrm{OR}=1.4,95 \%$ $\mathrm{CI}=1.1-1.7)$, spina bifida $(\mathrm{OR}=2.0,95 \% \mathrm{CI}=1.3-3.2)$, and gastroschisis $(\mathrm{OR}=1.8,95 \% \mathrm{CI}=1.1-2.9)$ (9).

Birth Defects Study to Evaluate Pregnancy Exposures. Increased interest in maternal chronic conditions and the need for more specific information regarding medication exposure, including the timing and dosage of medication used during pregnancy, led to the establishment of a successor project to the NBDPS: the Birth Defects Study to Evaluate Pregnancy exposures (BD-STEPS). This study further examines findings from the NBDPS and follows up on leads to understand more about what causes 17 major birth defects and how to prevent them. Using a computer-assisted telephone interview, BD-STEPS began collecting data on children born on or after January 1, 2014.

Treating for Two: Safer Medication Use in Pregnancy. Launched in 2012, CDC's Treating for Two initiative ${ }^{\dagger}$ is striving to expand medication research, develop medication guidance, and provide timely information to prescribers, pharmacists, patients, and consumers. Ultimately, the Treating for Two Initiative aims to identify treatments that balance therapeutic efficacy with fetal safety to provide guidance on which medications are safer alternatives to commonly used

\footnotetext{
${ }^{\dagger}$ Additional information available at http://www.cdc.gov/pregnancy/meds/ treatingfortwo.
}

potentially teratogenic medications for management of common conditions before and during pregnancy.

The Birth Defects Study/Pregnancy Health Interview Study - Slone Epidemiology Center, Boston University. The safety of medications used to treat specific conditions or illness during pregnancy generally is unknown because pregnant woman typically are excluded from clinical trials conducted before medication marketing. However, treating or preventing illness in pregnant women is important, as such conditions might be unsafe for both the mother and the developing child. The Birth Defects Study (BDS) of Boston University's Slone Epidemiology Center is a multicenter casecontrol study principally focused on medication exposures during pregnancy. The outcomes of primary interest include a wide range of specific birth defects, as well as other complications of pregnancy. Initiated in 1976, the study collects detailed information through telephone interviews of mothers who have had infants with major birth defects and mothers who have had infants without birth defects. Since its inception, BDS has interviewed approximately 50,000 women. Among its findings are associations between first trimester opioid use and neural tube defects $(\mathrm{OR}=2.2,95 \% \mathrm{CI}=1.2-4.2)(10)$, and between topiramate (an antiepileptic) and cleft lip with or without cleft palate $(\mathrm{OR}=10.1,95 \% \mathrm{CI}=1.1-129.2)(11)$.

Vaccines and Medications in Pregnancy Surveillance System. Concerns about birth defects play a particular role in public health efforts directed at emergency preparedness. In the case of pandemic influenza, for example, pregnant women might be reluctant to receive vaccines or to take anti-influenza antiviral medications because of fear about potential adverse effects on their pregnancy and offspring. To provide critical safety surveillance in such situations, in 2009, the American Academy of Asthma, Allergy, and Immunology, Boston University, and the Organization of Teratology Information Specialists created the Vaccines and Medications in Pregnancy Surveillance System (VAMPSS). VAMPSS conducts contemporaneous studies using two study designs: 1) a cohort (pregnancy registry) study of pregnant women exposed to selected vaccines and medications, with detailed information regarding dose, gestational timing, and duration (outcomes include a wide range of adverse pregnancy outcomes, including birth defects) and 2) a case-control study using Boston University's BDS, focused on risks and safety of vaccines, medications, and other exposures with respect to specific birth defects. VAMPSS thus can monitor safety of interventions during widespread uptake of vaccines or medications in response to a public health emergency. Importantly, VAMPSS is able to quickly incorporate studies of vaccine and medication safety in pregnant women at the outset of an emergency response, and accumulating data are provided to the VAMPSS Independent 
Advisory Committee within a short timeframe. Anticipating a widespread exposure to the pandemic $\mathrm{H} 1 \mathrm{~N} 1$ ( $\mathrm{pH} 1 \mathrm{~N} 1$ ) vaccine during the 2009-2010 H1N1 influenza season, VAMPSS was asked to conduct studies examining vaccine risk in pregnancy. Data from the cohort arm of VAMPSS indicated that women exposed to the $\mathrm{pH} 1 \mathrm{~N} 1$ vaccine did not have an increased risk for having a child born with major birth defects in the aggregate (relative risk $=0.8,95 \% \mathrm{CI}=0.3-2.4)(12)$. With its inherent power, the case-control arm of VAMPSS had the capacity to study 41 specific birth defects, and for most, found risk estimates approximating 1.0 (13). Currently, VAMPSS studies annual influenza vaccines and anti-influenza antivirals; however, new vaccines or medications (e.g., medical countermeasures that might be used following a bioterrorism event) can be quickly incorporated into the two parallel studies.

\section{Demonstrating Impact on Birth Defects Prevention}

The story of folic acid fortification to prevent neural tube defects was a great public health achievement. Randomized controlled trials and observational studies demonstrated that folic acid intake during early pregnancy could protect against neural tube defects in the developing embryo $(14,15)$. On the basis of this knowledge, in 1992, the U.S. Public Health Service issued a recommendation that all women of childbearing potential consume $400 \mu \mathrm{g}$ of folic acid daily. In 1998, enriched cereal grain products were required to be fortified at $140 \mu \mathrm{g}$ of folic acid per $100 \mathrm{~g}$, and ready-to-eat cereals were allowed to be fortified with up to $400 \mu \mathrm{g}$ per serving. Immediately following mandatory fortification, the birth prevalence of neural tube defects declined. On the basis of data collected through 2011, folic acid fortification in the United States has been estimated to prevent neural tube defects in about 1,300 births each year or a total of approximately 15,000 prevented since 1999 (16).

In addition to estimating the impact of folic acid on reducing the prevalence of neural tube defects, mathematical modeling of other risk factors has provided insight into the potential impact of birth defects prevention efforts. Reductions in the prevalence of recognized or strongly suspected risk factors, such as pre-pregnancy obesity, uncontrolled pregestational diabetes, or tobacco use in early pregnancy, for example, have the potential to prevent a substantial proportion of birth defects, assuming a causal relationship (Table). Moreover, universal pre-conception care for women with diabetes, an intervention known to be effective in establishing glycemic control, in combination with screening to identify women of reproductive age for undiagnosed diabetes, could prevent approximately 3,700 birth defects each year, with approximately $\$ 1.5$ billion in averted lifetime direct and indirect costs (17). One challenge of modeling studies is that each exposure is examined in the
TABLE. Population attributable fraction estimates for pre-pregnancy and early pregnancy exposures and selected birth defects

\begin{tabular}{lccc}
\hline & & \multicolumn{2}{c}{ Population attributable fraction } \\
\cline { 3 - 4 } Birth defect & Exposure & $\%$ & $\begin{array}{c}(95 \% \\
\text { uncertainty } \\
\text { interval) }\end{array}$ \\
\hline $\begin{array}{c}\text { Congenital heart } \\
\text { defects }\end{array}$ & $\begin{array}{c}\text { Pre-pregnancy } \\
\text { obesity }\end{array}$ & $8^{*}$ & $(3-14)$ \\
$\begin{array}{c}\text { Congenital heart } \\
\text { defects } \\
\text { Spina bifida }\end{array}$ & $\begin{array}{c}\text { Pregestational } \\
\text { diabetes } \\
\text { Pre-pregnancy } \\
\text { obesity }\end{array}$ & $8^{\dagger}$ & $(6-12)$ \\
$\begin{array}{c}\text { Cleft lip with or } \\
\text { without cleft } \\
\text { palate }\end{array}$ & $\begin{array}{c}\text { Pre-pregnancy } \\
\text { obesity }\end{array}$ & $6^{*}$ & $(21-34)$ \\
Orofacial clefts & $\begin{array}{c}\text { Early pregnancy } \\
\text { smoking }\end{array}$ & $6^{\S}$ & $(1-11)$ \\
\hline
\end{tabular}

* Honein MA, Devine O, Sharma AJ, et al. Modeling the potential public health impact of pre-pregnancy obesity on adverse fetal and infant outcomes. Obesity 2013;21:1276-83.

† Simeone RM, Devine OJ, Marcinkevage JA, et al. Diabetes and congenital heart defects: a systematic review, meta-analysis, and modeling project. Am J Prev Med 2015;48:195-204.

$\S$ Honein MA, Devine O, Grosse SD, Reefhuis J. Prevention of orofacial clefts caused by smoking: implications of the Surgeon General's report. Birth Defects Res A Clin Mol Teratol 2014;100:822-5.

absence of other known teratogens; the impact of addressing all these birth defects risk factors simultaneously is still unknown.

Although knowledge of birth defects risk factors has increased, the causes of the majority of birth defects remain unknown. Studies investigating risk factors early in pregnancy are hampered by numerous methodologic challenges. Moreover, although birth defects are collectively common, individual birth defects are rare and likely arise from different exposures, requiring separate investigations. Despite these challenges, the observed success of folic acid fortification and mathematical modeling studies indicate that research focused on identifying causes such as uncontrolled pregestational diabetes and tobacco use in early pregnancy, as well as reducing the prevalence of strongly suspected teratogens, such as obesity, can prevent numerous birth defects and substantially reduce their public health burden.

\section{Acknowledgment}

Cynthia Moore, MD, PhD, Division of Birth Defects and Developmental Disabilities, National Center on Birth Defects and Developmental Disabilities, CDC.

\footnotetext{
${ }^{1}$ Division of Birth Defects and Developmental Disabilities, National Center on Birth Defects and Developmental Disabilities, CDC; ${ }^{2}$ Division of Medical Genetics, Department of Pediatrics, University of Utah School of Medicine; ${ }^{3}$ Slone Epidemiology Center at Boston University; ${ }^{4}$ Office of the Associate Director for Science, CDC.

Corresponding author: Regina Simeone, uzx8@cdc.gov, 404-498-3901.
} 


\section{References}

1. CDC. Update on overall prevalence of major birth defects-Atlanta, Georgia, 1978-2005. MMWR Morb Mortal Wkly Rep 2008;57:1-5.

2. Kucik JE, Alverson CJ, Gilboa SM, Correa A. Racial/ethnic variations in the prevalence of selected major birth defects, metropolitan Atlanta, 1994-2005. Public Health Rep 2012;127:52-61.

3. Broussard CS, Gilboa SM, Lee KA, Oster M, Petrini JR, Honein MA. Racial/ethnic differences in infant mortality attributable to birth defects by gestational age. Pediatrics 2012;130:e518-27.

4. Russo CA, Elixhauser A. Hospitalizations for birth defects, 2004. Rockville, MD: US Agency for Healthcare Research and Quality; 2007. Available at https://www.hcup-us.ahrq.gov/reports/statbriefs/sb24.pdf.

5. CDC. Hospital stays, hospital charges, and in-hospital deaths among infants with selected birth defects-United States, 2003. MMWR Morb Mortal Wkly Rep 2007;56:25-9.

6. Holmes LB. Human teratogens: update 2010. Birth Defects Res A Clin Mol Teratol 2011;91:1-7.

7. Reefhuis J, Gilboa SM, Anderka M, et al. The national birth defects prevention study: A review of the methods. Birth Defects Res A Clin Mol Teratol 2015;103:656-69.

8. Correa A, Gilboa SM, Besser LM, et al. Diabetes mellitus and birth defects. Am J Obstet Gynecol 2008;199:237e1-9.

9. Broussard CS, Rasmussen SA, Reefhuis J, et al. Maternal treatment with opioid analgesics and risk for birth defects. Am J Obstet Gynecol 2011;204:314e1-11.
10. Yazdy MM, Mitchell AA, Tinker SC, Parker SE, Werler MM. Periconceptional use of opioids and the risk of neural tube defects. Obstet Gynecol 2013;122:838-44.

11. Margulis AV, Mitchell AA, Gilboa SM, et al. Use of topiramate in pregnancy and risk of oral clefts. Am J Obstet Gynecol 2012;207:405e1-7.

12. Chambers CD, Johnson D, Xu R, et al. Risks and safety of pandemic $\mathrm{H} 1 \mathrm{~N} 1$ influenza vaccine in pregnancy: birth defects, spontaneous abortion, preterm delivery, and small for gestational age infants. Vaccine 2013;31:5026-32.

13. Louik C, Ahrens K, Kerr S, et al. Risks and safety of pandemic H1N1 influenza vaccine in pregnancy: exposure prevalence, preterm delivery, and specific birth defects. Vaccine 2013;31:5033-40.

14. MRC Vitamin Study Research Group. Prevention of neural tube defects: results of the Medical Research Council Vitamin Study. Lancet 1991;338:131-7.

15. Blencowe H, Cousens S, Modell B, Lawn J. Folic acid to reduce neonatal mortality from neural tube disorders. Int J Epidemiol 2010;39(Suppl 1): i110-21.

16. Williams J, Mai CT, Mulinare J, et al. Updated estimates of neural tube defects prevented by mandatory folic acid fortification-United States, 1995-2011. MMWR Morb Mortal Wkly Rep 2015;64:1-5.

17. Peterson C, Grosse SD, Li R, et al. Preventable health and cost burden of adverse birth outcomes associated with pregestational diabetes in the United States. Am J Obstet Gynecol 2015;212:74e1-9. 


\title{
Establishment of an Ebola Treatment Unit and Laboratory - Bombali District, Sierra Leone, July 2014-January 2015
}

\author{
Brigette Gleason, $\mathrm{MD}^{1}$; John Redd, $\mathrm{MD}^{2}$; Peter Kilmarx, $\mathrm{MD}^{3,4}$; Tom Sesay, MD5; Francis Bayor ${ }^{5}$; Antons Mozalevskis, $\mathrm{MD}^{6}$; \\ Allison Connolly ${ }^{6}$; James Akpablie, MD ${ }^{6}$; Dimitri Prybylski, PhD ${ }^{3,7}$; Daphne Moffett, $\mathrm{PhD}^{3,8}$; Michael King, PhD ${ }^{9}$; Micah Bass ${ }^{10}$; Kristy Joseph ${ }^{3}$; \\ Jefferson Jones, $\mathrm{MD}^{1}$; Francis Ocen ${ }^{11}$
}

The first confirmed case of Ebola virus disease (Ebola) in Sierra Leone related to the ongoing epidemic in West Africa occurred in May 2014, and the outbreak quickly spread (1). To date, 8,704 Ebola cases and 3,955 Ebola deaths have been confirmed in Sierra Leone (2). The first Ebola treatment units (ETUs) in Sierra Leone were established in the eastern districts of Kenema and Kailahun, where the first Ebola cases were detected, and these districts were also the first to control the epidemic (3). By September and October 2014, districts in the western and northern provinces, including Bombali, had the highest case counts, but additional ETUs outside of the eastern province were not operational for weeks to months (3). Bombali became one of the most heavily affected districts in Sierra Leone, with 873 confirmed patients with Ebola during July-November 2014.*'The first ETU and laboratory in Bombali District were established in late November and early December 2014, respectively. To evaluate the impact of the first ETU and laboratory becoming operational in Bombali on outbreak control, the Bombali Ebola surveillance team assessed epidemiologic indicators before and after the establishment of the first ETU and laboratory in Bombali. After the establishment of the ETU and laboratory, the interval from symptom onset to laboratory result ${ }^{\dagger}$ and from specimen collection to laboratory result decreased. By providing treatment to Ebola patients and isolating contagious persons to halt ongoing community transmission, ETUs play a critical role in breaking chains of transmission and preventing uncontrolled spread of Ebola (4). Prioritizing and expediting the establishment of an ETU and laboratory by pre-positioning resources needed to provide capacity for isolation, testing, and treatment of Ebola are essential aspects of pre-outbreak planning.

Before the establishment of an ETU in Bombali, patient transfer to an ETU typically did not occur until there was laboratory confirmation of Ebola. ETUs in other districts were often filled to capacity, so patients in Bombali had to wait in holding centers, which had limited capacity to isolate patients (5), until ETU beds in other districts became available.

\footnotetext{
* On the basis of data in the viral hemorrhagic fever database for Sierra Leone, which is managed by the Sierra Leone Ministry of Health and Sanitation and CDC Data Team in Sierra Leone. Weekly updated sync files are shared among stakeholders of the Ebola Emergency.

${ }^{\dagger}$ Refers to when the laboratory result was available to the Sierra Leone Ministry of Health and Sanitation.
}

Ebola patients traveled 214-285 miles (344-459 km) from Bombali's holding centers (at least four hours by ambulance) to the nearest ETU in Kenema or Kailahun. Additionally, the closest laboratory was $>100$ miles $(>161 \mathrm{~km}$ ) away (a 3-4 hour drive), and samples were only taken to the laboratory once each day. Delays in diagnosis, isolation and treatment (measured by analyzing variables in the Ebola database managed by the Bombali surveillance team) decreased chances of survival $(\sigma)$ and delayed the institution of outbreak control measures. In 2012, CDC developed the viral hemorrhagic fever (VHF) tool, which runs on the Epi Info software platform to collect, manage, and analyze epidemiologic and laboratory data on outbreaks of viral hemorrhagic fevers, including Ebola (additional information available at https://epiinfovhf.codeplex. $\mathrm{com} /$ ). VHF is used in Sierra Leone as an Ebola database to manage data from Ebola case investigation forms, line lists of contacts for Ebola cases, and laboratory results; Bombali was one of the first districts in Sierra Leone to analyze Ebola outbreak data in realtime using VHF.

In September 2014, Bombali Ministry of Health and Sanitation (MoHS) staff, in collaboration with epidemiologists from CDC and the World Health Organization, began using data from Bombali's VHF database to assess timeliness of outbreak control, document changes in performance over time, identify gaps in response measures, and recommend action steps. The number of newly identified confirmed Ebola cases per week was calculated, plus the intervals from 1) symptom onset to case investigation, 2) symptom onset to patient isolation in an ETU or holding center, 3) symptom onset to laboratory result, 4) patient isolation to laboratory result, and 5) specimen collection to laboratory result. Records of patients with symptom onset during July 1-November 17, 2014, were analyzed to evaluate the timeframe before the establishment of the first ETU and laboratory in Bombali, and those with symptom onset dates during December 1, 2014-January 31, 2015 were analyzed to evaluate the period after ETU and laboratory establishment. Because the ETU became operational 2 weeks before the laboratory, records with reported symptom onset during November 18-30 were excluded from the time interval analysis, as were records with missing data elements that were components of the computed indicators. 


\section{Summary}

What is already known on this topic?

Many areas of West Africa have successfully controlled the Ebola outbreak at a local level through interventions, including establishment of laboratories and Ebola treatment units (ETUs) for testing and treating Ebola. Bombali was among the hardest hit districts in Sierra Leone during the Ebola epidemic, but outbreak control was achieved.

What is added by this report?

Data from the viral hemorrhagic fever (VHF) database demonstrated measurable improvements in timeliness of Ebola control measures in Bombali after the establishment of a local ETU and laboratory amidst ongoing community interventions. After establishment of the ETU and laboratory in Bombali, statistically significant reductions in the mean interval from symptom onset to laboratory result, from specimen collection to laboratory result, from patient isolation to laboratory result, and from symptom onset to case investigation were noted.

What are the implications for public health practice?

The VHF database can be used to analyze epidemiologic indicators both in real time and longitudinally to guide Ebola response efforts. Pre-positioning of laboratory capacity and health facilities that can be used for Ebola testing, isolation, and treatment during an outbreak might hasten outbreak control.

Epidemiologic indicator means were calculated and compared by using two-sided t-tests with an alpha level of 0.05 . The slope of the epidemic curve was analyzed by using Joinpoint software to identify statistically significant changes in trends over the course of the outbreak ( 7 ). Joinpoint software uses a regression model and permutation tests to fit the data starting with the minimum number of joinpoints, then testing for statistical significance of apparent trends by using an alpha-level of 0.05 when more joinpoints are added to the model ( 7 ).

The mean value for most indicators decreased after the first ETU and laboratory became operational in Bombali, demonstrating improvements in efforts to control the epidemic (Table). Improvements were seen in the mean interval from symptom onset to laboratory result, from specimen collection to laboratory result, from patient isolation to laboratory result, and from symptom onset to case investigation. The interval from symptom onset to isolation did not significantly change. Ebola weekly case counts by week of symptom onset decreased in late September (after a sharp increase beginning in the middle of the month) and again in late November to early December 2014 (Figure 1). Joinpoint analysis of the slope of the epidemic curve (Figure 2) demonstrated a statistically significant difference during the period after the first ETU and laboratory became operational compared with the preceding 9 weeks $(\mathrm{p}<0.01)$.
TABLE. Epidemiologic indicators among confirmed Ebola patients before and after the establishment of an Ebola treatment unit (ETU) and laboratory - Bombali District, Sierra Leone, July 2014-January 2015

\begin{tabular}{cccc}
\hline & $\begin{array}{c}\text { Before establishment } \\
\text { of ETU and } \\
\text { laboratory in } \\
\text { Bombali } \\
\text { (July 1- }\end{array}$ & $\begin{array}{c}\text { After establishment } \\
\text { of ETU and } \\
\text { laboratory in } \\
\text { Bombali }\end{array}$ & \\
$\begin{array}{c}\text { Epidemiologic } \\
\text { indicator (interval) }\end{array}$ & $\begin{array}{c}\text { November 17, 2014) } \\
\text { Mean interval in days }\end{array}$ & $\begin{array}{c}\text { January 31, 2014- } \\
\text { Mean interval in days }\end{array}$ & $\begin{array}{c}\text { p- } \\
\text { value }\end{array}$ \\
\hline $\begin{array}{c}\text { Symptom onset to } \\
\text { laboratory result }\end{array}$ & 7.3 & 5.2 & $<0.01$ \\
$\begin{array}{c}\text { Specimen collection } \\
\text { to laboratory result }\end{array}$ & 2.5 & 1.2 & $<0.01$ \\
$\begin{array}{c}\text { Patient isolation to } \\
\text { laboratory result }\end{array}$ & 3.7 & 1.5 & $<0.05$ \\
$\begin{array}{c}\text { Symptom onset to } \\
\text { case investigation }\end{array}$ & 4.4 & 3.6 & $<0.05$ \\
$\begin{array}{c}\text { Symptom onset to } \\
\text { patient isolation }\end{array}$ & 4.0 & 3.6 & $>0.05$ \\
\hline
\end{tabular}

\section{Discussion}

Death from untreated Ebola occurs a mean of 7.5 days after symptom onset, underscoring the need for rapid response (8). Before the establishment of the ETU in Bombali, specimen collection occurred at holding centers throughout the district and relied on availability of a laboratory technician and transport of the specimen to a laboratory, often by motorbike. Delay in receipt of laboratory results hindered the transfer of ill patients to ETUs, so patients waited in overcrowded holding facilities, which only accommodated separation of patients into groups based on confirmed, negative, and pending Ebola laboratory results (4). In addition, a single water supply for bathing and laundry contributed additional risks for exposure and transmission in certain holding centers. Before the ETU and laboratory opened in Bombali, the mean interval of 7.3 days from symptom onset to laboratory result meant infectious patients often were in the final stages of illness before an Ebola diagnosis was confirmed. Patients with Ebola are more infectious in late stages of illness (9), so rapid testing and appropriate isolation are essential to outbreak control. After the laboratory opened, testing capacity within the district allowed at least two specimen batches to be tested each day, and the interval from specimen collection to laboratory results decreased from 2.5 to 1.2 days (Table).

The weekly Ebola case count in Bombali decreased after establishment of the ETU (Figure 1). Multiple other public health interventions were implemented during SeptemberDecember 2014, which might have contributed to reduced Ebola case counts in Bombali. Interventions included increased access to ambulances, fuel, and food for affected communities; 
FIGURE 1. Number of confirmed cases of Ebola virus disease (Ebola) and establishment of first Ebola treatment unit, by week of symptom onset and key milestones* — Bombali District, Sierra Leone, June 29, 2014-January 31, 2015

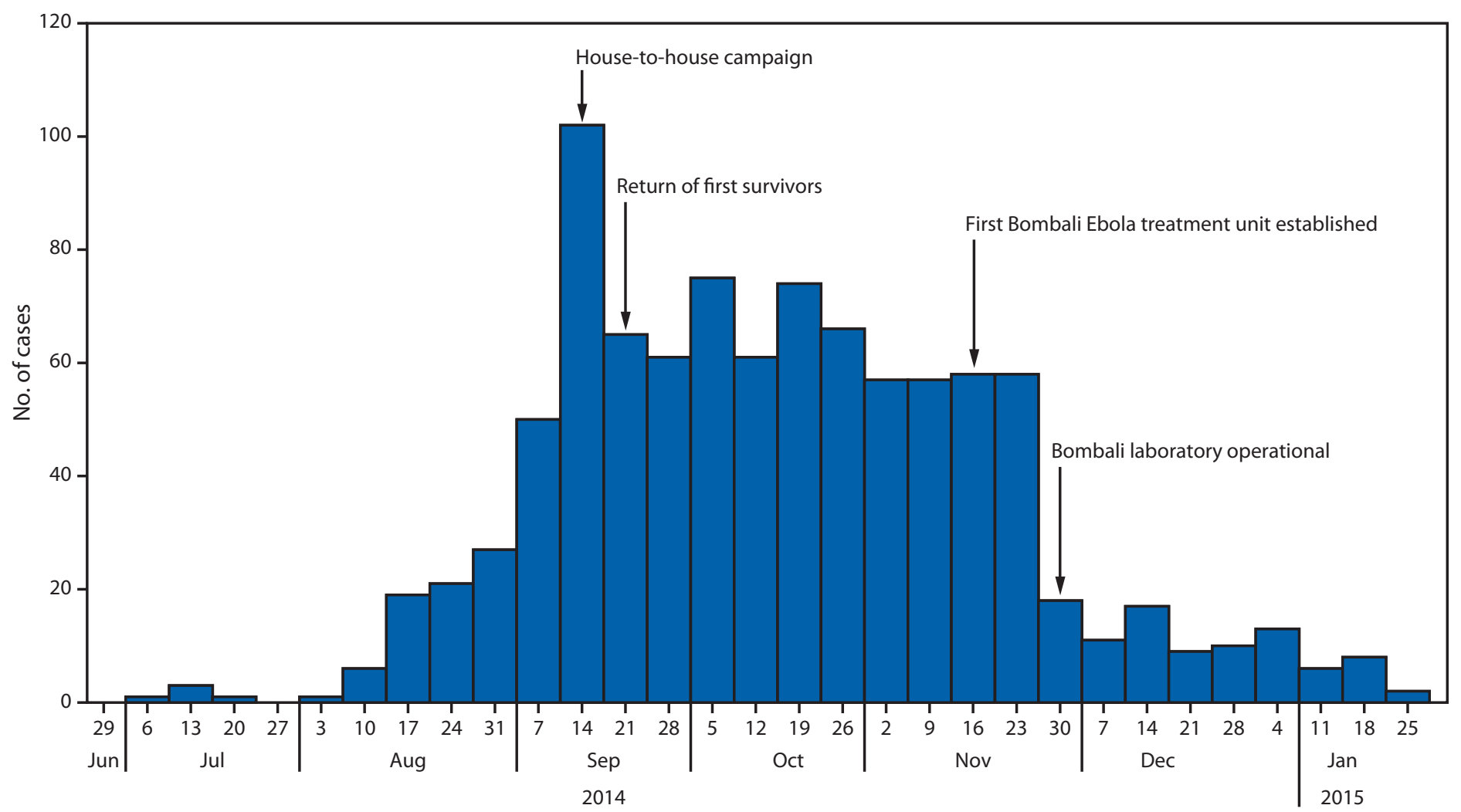

Week of symptom onset

\footnotetext{
* The house-to-house campaign during September 19-21, 2014, was organized by the Ministry of Health and Sanitation of Sierra Leone so that public health workers could visit every household in the country to educate residents about Ebola and to conduct active case finding. The return of the first survivors to Bombali on September 25, 2014, led to their participation in media messaging to promote the ideas that "Ebola is real" and that survival is possible if care is sought early.
}

increased human resources engaged in response efforts; community education; and consistent messaging through radio shows and advertisements. Beyond this, there was improved surveillance, case investigation, contact tracing and monitoring; better managed quarantine; survivors' involvement in the response; and improved infection prevention and control practices in health care facilities. Finally, a military command center was created and interactions improved between health educators, contact tracers, and the community.

The findings in this report are subject to at least three limitations. First, VHF data on patient outcome were often missing, especially during the early months of the epidemic. Therefore, it was not possible to correlate survival with establishment of the ETU and laboratory in Bombali. Second, because the VHF application does not capture information on burials performed by trained burial teams or quarantine, VHF could not be used to monitor the impact of safe medical burials or quarantine on the outbreak. Finally, because multiple public health interventions were performed simultaneously during this epidemic, it is not possible to know the independent contribution of each.

The findings are consistent with other investigations that highlight the importance of rapid case identification and isolation $(1,10)$. The World Health Organization has identified prompt detection and treatment of Ebola as key objectives of the outbreak response (10). Establishment of ETUs and laboratories at the onset of an Ebola outbreak in conjunction with other well-established control measures might prevent rapid increase in the number of Ebola cases and thereby contribute to outbreak control. An ETU and laboratory were not available during the first 5 months of the outbreak in Bombali, so emergency response planning for Ebola outbreaks might benefit from pre-positioning of resources to expedite operationalization of facilities that can accommodate Ebola testing, isolation, and treatment. 
FIGURE 2. Joinpoint analysis of the slope of the Ebola epidemiologic curve of the number of cases for the weeks September 21, 2014 (week 0) through January 31, 2015 (week 17) - Bombali District, Sierra Leone*

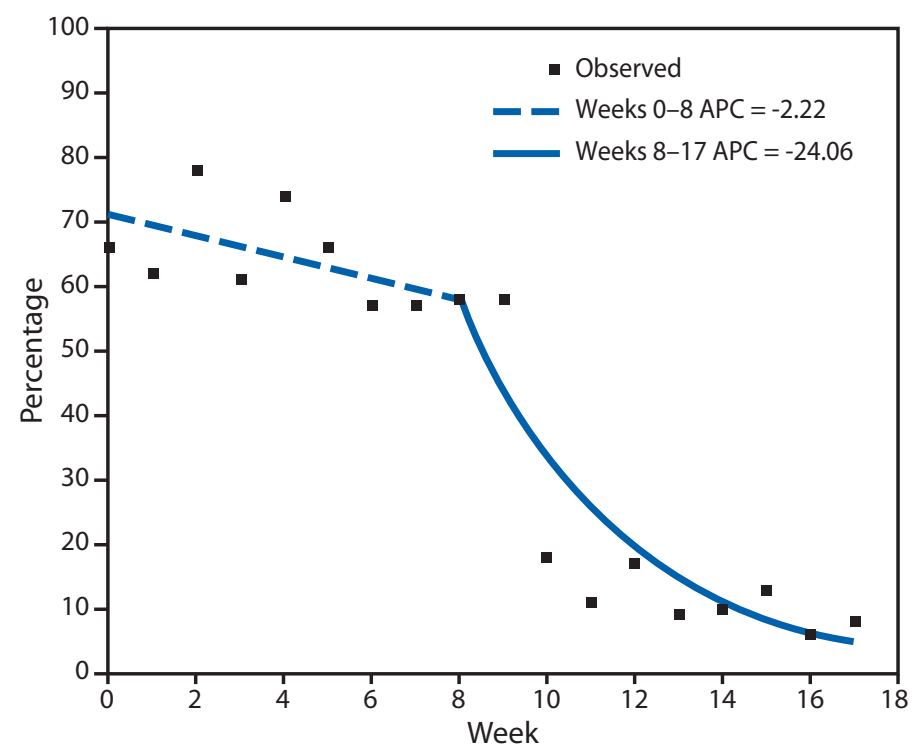

Abbreviation: $\mathrm{APC}=$ annual percentage change.

* The Bombali Ebola treatment unit opened on November 17, 2014 (week 8) and admitted the first seven confirmed patients on November 24 (week 9). The laboratory became operational on December 8, 2014 (week 11).

\section{Acknowledgments}

William Bower, Farah Husain, Sara Hersey, Ginger Chew, and the Bombali Surveillance Team of the Ministry of Health and Sanitation for Sierra Leone, Freetown.
${ }^{1}$ Epidemic Intelligence Service, CDC; ${ }^{2}$ Office of Public Health Preparedness and Response, CDC; ${ }^{3}$ Center for Global Health, CDC; ${ }^{4} \mathrm{CDC}$ Zimbabwe; ${ }^{5}$ Sierra Leone Ministry of Health and Sanitation, Bombali District; ${ }^{6}$ Ebola Response Bombali District, World Health Organization; ${ }^{7} \mathrm{CDC}$ Namibia; ${ }^{8}$ CDC Tanzania; ${ }^{9}$ Center for Surveillance, Epidemiology and Laboratory Services, CDC; ${ }^{10}$ National Center for Immunization and Respiratory Disease, CDC; ${ }^{11}$ African Union.

Corresponding author: Brigette Gleason, yer7@cdc.gov, 804-864-7264.

\section{References}

1. Dixon MG, Schafer IJ. Ebola viral disease outbreak-West Africa, 2014. MMWR Morb Mortal Wkly Rep 2014;63:548-51.

2. CDC. 2014 Ebola outbreak in West Africa—case counts. Atlanta, GA: US Department of Health and Human Services, CDC; 2014. Available at http:// www.cdc.gov/vhf/ebola/outbreaks/2014-west-africa/case-counts.html.

3. World Health Organization. Ebola response roadmap situation report: 1 October 2014. Available at http://reliefweb.int/sites/reliefweb.int/files/ resources/roadmapsitrep_1Oct2014_eng.pdf.

4. Medecins Sans Frontieres. MSF opens new Ebola treatment centers in Sierra Leone to increase access to care. Available at http://www.doctorswithoutborders.org/article/ msf-opens-new-ebola-treatment-centers-sierra-leone-increase-access-care.

5. Pathmanathan I, O'Connor KA, Adams ML, et al. Rapid assessment of Ebola infection prevention and control needs - six districts, Sierra Leone, October 2014. MMWR Morb Mortal Wkly Rep 2014;63:1172-4.

6. Fowler RA, Fletcher T, Fischer WA 2nd, et al. Caring for critically ill patients with Ebola virus disease. Perspectives from West Africa. Am J Respir Crit Care Med 2014;190:733-7.

7. National Cancer Institute. Joinpoint Regression Program, Version 4.2.0. Washington, DC: National Institutes of Health, National Cancer Institute; 2015.

8. CDC. Ebola virus disease information for clinicians in U.S healthcare settings. Atlanta, GA: US Department of Health and Human Services, CDC; 2015. Available at http://www.cdc.gov/vhf/ebola/hcp/clinicianinformation-us-healthcare-settings.html.

9. Osterholm MT, Moore KA, Kelley NS, et al. Transmission of Ebola viruses: what we know and what we do not know. MBio 2015;6:e00137-15.

10. World Health Organization. Ebola response roadmap. WHO/ EVD/Roadmap/14.1. Available at http://apps.who.int/iris/ bitstream/10665/131596/1/EbolaResponseRoadmap.pdf. 


\title{
Vital Signs: Improvements in Maternity Care Policies and Practices That Support Breastfeeding — United States, 2007-2013
}

\author{
Cria G. Perrine, $\mathrm{PhD}^{1}$; Deborah A. Galuska, $\mathrm{PhD}^{1}$; Jaime L. Dohack, MS²; Katherine R. Shealy, MPH${ }^{1}$; Paulette E. Murphy, MLIS ${ }^{1}$; \\ Laurence M. Grummer-Strawn, $\mathrm{PhD}^{3}$; Kelley S. Scanlon, $\mathrm{PhD}^{1}$ \\ On October 6, 2015, this report was posted as an MMWR Early Release on the MMWR website (http://www.cdc.gov/mmwr).
}

\section{Abstract}

Background: Although $80 \%$ of U.S. mothers begin breastfeeding their infants, many do not continue breastfeeding as long as they would like to. Experiences during the birth hospitalization affect a mother's ability to establish and maintain breastfeeding. The Baby-Friendly Hospital Initiative is a global program launched by the World Health Organization and the United Nations Children's Fund, and has at its core the Ten Steps to Successful Breastfeeding (Ten Steps), which describe evidence-based hospital policies and practices that have been shown to improve breastfeeding outcomes.

Methods: Since 2007, CDC has conducted the biennial Maternity Practices in Infant Nutrition and Care (mPINC) survey among all birth facilities in all states, the District of Columbia, and territories. CDC analyzed data from 2007 (baseline), 2009, 2011, and 2013 to describe trends in the prevalence of facilities using maternity care policies and practices that are consistent with the Ten Steps to Successful Breastfeeding.

Results: The percentage of hospitals that reported providing prenatal breastfeeding education (range $=91.1 \%-92.8 \%$ ) and teaching mothers breastfeeding techniques (range $=87.8 \%-92.2 \%$ ) was high at baseline and across all survey years. Implementation of the other eight steps was lower at baseline. From 2007 to 2013, six of these steps increased by 10-21 percentage points, although limiting non-breast milk feeding of breastfed infants and fostering post-discharge support only increased by 5-6 percentage points. Nationally, hospitals implementing more than half of the Ten Steps increased from $28.7 \%$ in 2007 to $53.9 \%$ in 2013.

Conclusions: Maternity care policies and practices supportive of breastfeeding are improving nationally; however, more work is needed to ensure all women receive optimal breastfeeding support during the birth hospitalization.

Implications for Public Health Practice: Because of the documented benefits of breastfeeding to both mothers and children, and because experiences in the first hours and days after birth help determine later breastfeeding outcomes, improved hospital policies and practices could increase rates of breastfeeding nationwide, contributing to improved child health.

\section{Introduction}

The American Academy of Pediatrics recommends that infants be exclusively breastfed (i.e., breast milk with no solids or other liquids except vitamin/mineral supplements or medications) for about the first 6 months of life, and that they continue to be breastfed for at least 12 months, with introduction of nutrient-rich complementary foods at about age 6 months (1). Eighty percent of infants in the United States begin breastfeeding (2); however, by age 6 months, just over half of all infants are receiving any breast milk, and only $21.9 \%$ exclusively breastfeed for the recommended first 6 months of life (2). These low rates of exclusive and continued breastfeeding have implications for public health: babies who are breastfed are at a reduced risk for ear, respiratory, and gastrointestinal infections; asthma; sudden infant death syndrome; and necrotizing enterocolitis $(3,4)$. In addition, evidence suggests that breastfeeding is associated with a reduction in the risk for obesity and diabetes in children (3). Mothers who breastfeed have a reduced risk for breast and ovarian cancers, diabetes, and cardiovascular disease $(3,5)$. The health effects for both mothers and infants from suboptimal breastfeeding rates contribute substantially to health care costs $(6,7)$.

Sixty percent of mothers who stopped breastfeeding during the first year reported that they stopped earlier than they desired (8). Lactation is a time-sensitive physiologic process, and experiences in the first hours and days after birth affect a mother's ability to continue breastfeeding after she leaves the hospital (9). Recognizing this, in 1991, the World Health Organization (WHO) and United Nations Children's Fund (UNICEF) established the Baby-Friendly Hospital Initiative. To be designated as Baby-Friendly, a hospital must implement the Ten Steps to Successful Breastfeeding (Ten Steps) and 
comply with the International Code of Marketing of Breastmilk Substitutes, which requires hospitals to pay fair market value for infant formula and not promote items detrimental to breastfeeding (10). The Ten Steps outline evidence-based maternity care policies and practices that have been shown to increase rates of breastfeeding initiation, duration, and exclusivity $(11,12)$. The American Academy of Pediatrics endorsed the Ten Steps in 2009.* In 2011 CDC produced a Vital Signs report showing hospital adherence to the Tens Steps in 2007 and 2009 (13); this report updates that information with additional data from 2011 and 2013.

\section{Methods}

Since 2007, CDC has conducted the biennial Maternity Practices in Infant Nutrition and Care (mPINC) survey, under contract with Battelle, to characterize U.S. maternity practices related to breastfeeding. The mPINC survey is a census administered to all birth facilities in all states, the District of Columbia, and U.S. territories (states). The response rate for the mPINC surveys to date has exceeded $80 \%$, with 2,665-2,742 facilities participating in each survey. Approximately $95 \%$ of participating facilities are hospitals, and the remainder are freestanding birth centers; in this report, the term "hospital" is used to refer to all facilities. For each survey cycle, the mPINC survey is sent to a member of the hospital staff who is identified during a screening telephone call as the person best able to answer questions about the hospital's routine maternity care and infant feeding practices. Respondents are encouraged to obtain input from other key staff in completing the survey. Each participating hospital receives an individualized report ${ }^{\dagger}$ showing how its practices compare with other hospitals nationally, in the same state, and of a similar size.

CDC identified 10 indicators in the mPINC survey consistent with WHO/UNICEF's Ten Steps to Successful Breastfeeding. These indicators are 1) existence of a model breastfeeding policy, 2) staff competency assessment, 3) prenatal breastfeeding education, 4) early initiation of breastfeeding, 5) teaching breastfeeding techniques, 6) limited provision of non-breastmilk fluids for healthy breastfed infants, 7) rooming-in, 8) teaching feeding cues, 9) limited use of pacifiers, and 10) post-discharge support. CDC calculated the percentage of hospitals implementing these steps in 2007 (baseline), 2009, 2011, and 2013 to describe trends in U.S. maternity care policies and practices that support breastfeeding and, among hospitals with complete data for all Ten Steps $(\mathrm{n}=2,181-2,479)$, the percentage implementing more than half of the Ten Steps, nationally and by state. In

\footnotetext{
* Available at http://www2.aap.org/breastfeeding/files/pdf/TenStepswosig.pdf.

${ }^{\dagger}$ Available at http://www.cdc.gov/breastfeeding/pdf/mpinc/sample-benchmarkreport.pdf.
}

the U.S. territories other than Puerto Rico, only one to three hospitals exist; because CDC does not share hospital identifiable information publicly, data from American Samoa, Guam, the Northern Mariana Islands, and the Virgin Islands are presented in aggregate as "island territories." In 2007, only one island territory hospital had data on all of the Ten Steps; therefore, the percentage of island territory hospitals implementing more than half of the Ten Steps is not presented for 2007. Thus a total of 52 states were included in the state-level analysis in 2007, and 53 states were included in all other survey years. No inferential statistics were calculated, as mPINC is a census, not a sample.

\section{Results}

At baseline and across survey years, most U.S. hospitals reported providing prenatal breastfeeding education (range $=91.1 \%-92.8 \%)$ and teaching mothers breastfeeding techniques (range $=87.8 \%-92.2 \%$ ) (Table). Reported implementation of the eight other steps was lower at baseline. For six of these steps, substantial improvement in reported hospital implementation occurred from 2007 to 2013 , including having a model breastfeeding policy (11.7\% to $26.3 \%)$, assessment of staff competency ( $44.6 \%$ to $60.2 \%)$, early initiation of breastfeeding ( $43.5 \%$ to $64.8 \%$ ), rooming-in $(30.8 \%$ to $44.8 \%$ ), teaching feeding cues $(77.0 \%$ to $87.3 \%)$, and limiting use of pacifiers $(25.3 \%$ to $45.0 \%)$. However, less progress occurred in limiting non-breast milk feeding of breastfed infants $(20.6 \%$ to $26.4 \%$ ), and in providing optimal post-discharge support (26.8\% to $32.2 \%)$. Nationally, the percentage of hospitals reporting implementing more than half of the Ten Steps increased from $28.7 \%$ in 2007 to $53.9 \%$ in 2013, and this increase was reported across states. From 2007 to 2013 the number of states with $\geq 60 \%$ of hospitals implementing more than half of the steps increased from 4 to 21 (Figure). In contrast, the number of states with $<20 \%$ of hospitals implementing more than half of the steps decreased from 15 to 0 .

\section{Conclusion and Comments}

From 2007 to 2013, several key aspects of maternity care supportive of breastfeeding have shown consistent improvement. Individualized mPINC reports sent to each participating hospital compare the hospitals' maternity care policies and practices with recommended standards, describe the evidence behind these standards, and identify improvement opportunities. Dissemination of these individualized reports, as well as dissemination of surveillance data from the mPINC survey, including state reports ${ }^{\S}$ and key publications (13), might have contributed to these improvements in maternity care practices. The Surgeon General's Call to Action to Support Breastfeeding,

\footnotetext{
\$Available at http://www.cdc.gov/breastfeeding/data/mpinc/state_reports.html. SAvailable at http://www.surgeongeneral.gov/library/calls/breastfeeding/ calltoactiontosupportbreastfeeding.pdf.
} 
TABLE. Percentage of hospitals with ideal practice on indicators of the Ten Steps to Successful Breastfeeding, CDC's Maternity Practices in Infant Nutrition and Care (mPINC) survey, by year — United States,* 2007-2013

\begin{tabular}{|c|c|c|c|c|c|}
\hline \multirow[b]{2}{*}{ Ten Steps to Successful Breastfeeding } & \multirow[b]{2}{*}{ mPINC Indicator } & \multicolumn{4}{|c|}{$\%$ of hospitals } \\
\hline & & $\begin{array}{c}2007 \\
(n=2,679)^{\dagger}\end{array}$ & $\begin{array}{c}2009 \\
(n=2,665)^{\dagger}\end{array}$ & $\begin{array}{c}2011 \\
(n=2,742)^{\dagger}\end{array}$ & $\begin{array}{c}2013 \\
(n=2,667)^{\dagger}\end{array}$ \\
\hline $\begin{array}{l}\text { 1. Have a written breastfeeding policy } \\
\text { that is routinely communicated to all } \\
\text { health care staff }\end{array}$ & $\begin{array}{l}\text { Model breastfeeding policy: Hospital has a written } \\
\text { breastfeeding policy that includes } 10 \text { model policy elements }\end{array}$ & 11.7 & 14.4 & 19.3 & 26.3 \\
\hline $\begin{array}{l}\text { 2. Train all health care staff in skills } \\
\text { necessary to implement this policy }\end{array}$ & $\begin{array}{l}\text { Staff competency assessment: Nurses/birth attendants are } \\
\text { assessed for competency in basic breastfeeding management } \\
\text { and support at least once per year }\end{array}$ & 44.6 & 49.7 & 54.9 & 60.2 \\
\hline $\begin{array}{l}\text { 3. Inform all pregnant women about the } \\
\text { benefits and management of } \\
\text { breastfeeding }\end{array}$ & $\begin{array}{l}\text { Prenatal breastfeeding education: Breastfeeding education is } \\
\text { included as a routine element of prenatal classes }\end{array}$ & 92.5 & 92.8 & 92.8 & 91.1 \\
\hline $\begin{array}{l}\text { 4. Help mothers initiate breastfeeding } \\
\text { within one hour of birth }\end{array}$ & $\begin{array}{l}\text { Early initiation of breastfeeding: } \geq 90 \% \text { of healthy full-term } \\
\text { breastfed infants initiate breastfeeding within one hour of } \\
\text { uncomplicated vaginal birth }\end{array}$ & 43.5 & 50.9 & 56.5 & 64.8 \\
\hline $\begin{array}{l}\text { 5. Show mothers how to breastfeed, and } \\
\text { how to maintain lactation, even if they } \\
\text { should be separated from their infants }\end{array}$ & $\begin{array}{l}\text { Teach breastfeeding techniques: } \geq 90 \% \text { of mothers who are } \\
\text { breastfeeding or intend to breastfeed are taught breastfeeding } \\
\text { techniques (e.g., positioning, how to express milk, etc.) }\end{array}$ & 87.8 & 89.1 & 90.8 & 92.2 \\
\hline $\begin{array}{l}\text { 6. Give breastfeeding newborn infants } \\
\text { no food or drink other than } \\
\text { breastmilk, unless medically indicated }\end{array}$ & $\begin{array}{l}\text { Limited non-breast milk feeds of breastfed infants: }<10 \% \text { of } \\
\text { healthy full-term breastfed infants are given formula, glucose } \\
\text { water, or water }\end{array}$ & 20.6 & 21.5 & 23.0 & 26.4 \\
\hline $\begin{array}{l}\text { 7. Practice rooming-in-allow mothers } \\
\text { and infants to remain together } 24 \\
\text { hours per day }\end{array}$ & $\begin{array}{l}\text { Rooming-in: } \geq 90 \% \text { of healthy full-term infants, regardless of } \\
\text { feeding method, remain with their mother for at least } 23 \text { hours } \\
\text { per day during the hospital stay }\end{array}$ & 30.8 & 33.2 & 37.0 & 44.8 \\
\hline 8. Encourage breastfeeding on demand & $\begin{array}{l}\text { Teach feeding cues: } \geq 90 \% \text { of mothers are taught to recognize and } \\
\text { respond to infant feeding cues instead of feeding on a set schedule }\end{array}$ & 77.0 & 81.8 & 84.8 & 87.3 \\
\hline $\begin{array}{l}\text { 9. Give no artificial teats or pacifiers to } \\
\text { breastfeeding infants }\end{array}$ & $\begin{array}{l}\text { Limited use of pacifiers: }<10 \% \text { of healthy full-term breastfed } \\
\text { infants are given pacifiers by maternity care staff }\end{array}$ & 25.3 & 30.1 & 36.3 & 45.0 \\
\hline $\begin{array}{l}\text { 10. Foster the establishment of } \\
\text { breastfeeding support groups and } \\
\text { refer mothers to these groups on } \\
\text { discharge from the hospital or clinic }\end{array}$ & $\begin{array}{l}\text { Post-discharge support: Hospital routinely provides } 3 \text { modes of } \\
\text { post-discharge support to breastfeeding mothers: physical } \\
\text { contact, active reaching out, and referrals }\end{array}$ & 26.8 & 26.8 & 28.4 & 32.2 \\
\hline \multicolumn{6}{|c|}{$\begin{array}{l}\text { * Includes United States, District of Columbia, and U.S. territories. } \\
\text { † } \mathrm{n} \text { varies slightly for each of the prevalence estimates. } \\
\S \text { Model policy elements are 1) in-service training, 2) prenatal breastfeeding classes, 3) asking about mothers' feeding plans, 4) initiating breastfeeding within one } \\
\text { hour of uncomplicated vaginal birth, 5) initiating breastfeeding after recovery for uncomplicated Cesarean sections and/or showing mothers how to express milk } \\
\text { and maintain lactation if separated from infant, 6) giving only breast milk to breastfed infants, 7) rooming-in } 24 \text { hr/day, 8) breastfeeding on demand, 9) no pacifier } \\
\text { use by breastfed infants, 10) referral of mothers with breastfeeding problems and/or referral of mothers to appropriate breastfeeding resources at discharge. } \\
\text { 9 Physical contact = home visit, hospital postpartum follow-up visit; active reaching out = follow-up phone call to patient after discharge; referrals = hospital phone } \\
\text { number to call, hospital-based support group, other breastfeeding support group, lactation consultant/specialist, U.S. Department of Agriculture Special Supplemental } \\
\text { Nutrition Proaram for Women, Infants, and Children, outpatient clinic. }\end{array}$} \\
\hline
\end{tabular}

the National Prevention Strategy, ${ }^{* *}$ and the addition of maternity care objectives to Healthy People $2020^{\dagger \dagger}$ have also helped increase focus on the importance of maternity care in helping women establish breastfeeding.

A variety of other efforts are also likely contributing to the observed improvements in maternity care. As stated earlier, to be designated as Baby-Friendly, a hospital must implement the Ten Steps to Successful Breastfeeding and comply with the International Code of Marketing of Breast-milk Substitutes (10). In 2011, as part of the First Lady's Let's Move! in Indian Country campaign, the Indian Health Service committed to achieving Baby-Friendly designation for all 13 of its federal

\footnotetext{
** Available at http://www.surgeongeneral.gov/priorities/prevention/strategy/ healthy-eating.pdf.

$\dagger \dagger$ Available at http://www.healthypeople.gov/2020/topics-objectives/topic/ maternal-infant-and-child-health/objectives.
}

maternity hospitals, a goal that was recently achieved. $\$ \$$ Under a cooperative agreement with CDC, the National Institute for Children's Health Quality led the Best Fed Beginnings project, which helped 89 hospitals from 29 states work toward BabyFriendly designation. This effort recruited hospitals with a large number of annual births and which serve populations with lower breastfeeding rates. As of August 2015, 50 of these hospitals have been designated Baby-Friendly and approximately 155,000 additional babies are now born in Baby-Friendly hospitals each year. 99 Through funding agreements and technical assistance, CDC also supports state health departments

\footnotetext{
$\$ \$$ Available at http://www.ihs.gov/newsroom/pressreleases/2014pressreleases/ all13ihsobstetricfacilitiesdesignatedbabyfriendly.

99 Available at http://www.nichq.org/sitecore/content/breastfeeding/ breastfeeding/solutions/best-fed-beginnings.
} 
FIGURE. Percentage of hospitals implementing more than half of the Ten Steps to Successful Breastfeeding, ${ }^{*}$ by state or jurisdiction Maternity Practices in Infant Nutrition and Care (mPINC) Survey, United States, 2007-2013

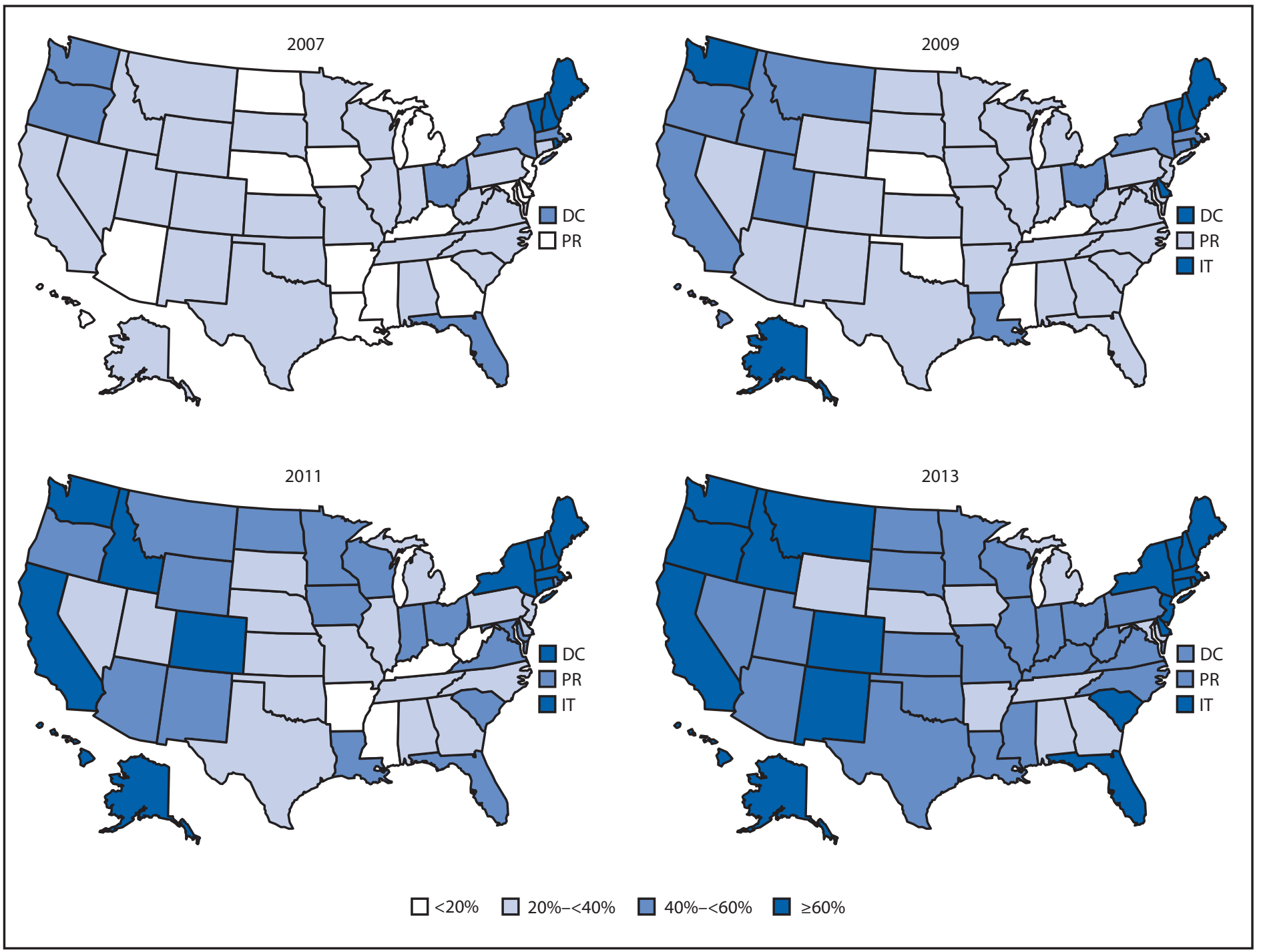

Abbreviations: DC = District of Columbia; IT = Island Territories, including American Samoa, Guam, Northern Mariana Islands, and Virgin Islands; PR = Puerto Rico. * These are mPINC indicators consistent with the Ten Steps to Successful Breastfeeding as described in the table.

in improving maternity care practices; currently 33 states are using CDC funds to improve maternity care practices that support breastfeeding.

Despite substantial improvement, as of 2013, implementation of several of these maternity care practices and policies was far from optimal. Just over one quarter of hospitals have a model breastfeeding policy, which is the foundation for many of the other steps. In addition, fewer than half of hospitals reported routinely keeping healthy infants with their mothers throughout the hospital stay, a practice that allows mothers to become more familiar with their babies' hunger cues, and increases opportunities for breastfeeding (12).
This report also describes two key indicators that were low at baseline and showed less progress: limiting the provision of fluids other than breast milk to healthy breastfed infants and the provision of optimal post-discharge support. The provision of non-breast milk fluids to healthy breastfed infants has been associated with suboptimal breastfeeding behaviors, shorter breastfeeding duration, and mothers being less likely to meet their own breastfeeding intentions $(14,15)$. The percentage of hospitals that limited giving fluids other than breast milk to health breastfed infants increased from $20.6 \%$ in 2007 to $26.4 \%$ in 2013 . In recognizing the provision of non-breast milk fluids to breastfed infants as a quality-of-care issue, in 2010, The Joint Commission, a major organization that accredits and certifies U.S. hospitals, added exclusive breast 
milk feeding during the newborn's entire hospitalization as a new quality of care measure. In 2014 The Joint Commission required reporting of this measure by all hospitals with $\geq 1,100$ births per year, and as of January 2016, will require reporting by all hospitals with $\geq 300$ births per year, thus encompassing approximately $80 \%$ of all birth hospitals. ${ }^{* * *}$ Reporting of this measure might help increase awareness of the importance of exclusive breastfeeding, and reduce hospital provision of non-breast milk fluids to breastfeeding infants when there is no medical indication for it.

From 2007 to 2013, the percentage of hospitals providing adequate post-discharge support increased by only $20 \%$. Problems with breastfeeding, such as trouble getting the baby to latch, pain, and a perception of insufficient milk, are common among new mothers and are associated with shorter durations of breastfeeding (16). In a study of first-time mothers that assessed concerns with breastfeeding at several time points during the first 2 months of life, these problems were most pronounced at 3 and 7 days postpartum (16), which is after most women have left the hospital, but before they might be connected to other types of community support. These early breastfeeding problems can often be overcome with early support and management. To receive this support, however, mothers need to have a continuum of care that extends from the hospital to other providers and programs in the first few weeks postpartum.

The findings in this report are subject to at least three limitations. First, the survey is completed by a key respondent on behalf of each hospital and might not accurately reflect the hospital practices assessed. However, to ensure that the data obtained were of highest quality possible, CDC requested that the survey be sent to the person most knowledgeable about the hospital's maternity practices, and that it be completed in consultation with other knowledgeable persons. Second, although approximately $80 \%$ of hospitals participated in each survey, practices might differ between those that participated and those that did not. Third, the mPINC indicators included here are consistent with the Ten Steps to Successful Breastfeeding, but might not indicate implementation of each of the steps as required for Baby-Friendly designation. ${ }^{\dagger \dagger}$

The national improvements in maternity care supportive of breastfeeding from 2007 to 2013 are substantial; however, more work is needed to ensure that all women have access to evidence-based maternity care policies and practices supportive of breastfeeding. Currently, among the approximately four million babies born in the United States every year, only about $14 \%$ are born in Baby-Friendly hospitals, and as of August 2015, only

\footnotetext{
*** Available at http://www.jointcommission.org/assets/1/23/jconline_ June_24_2015.pdf.

t† Available at https://www.babyfriendlyusa.org/get-started/ the-guidelines-evaluation-criteria.
}

\section{Key Points}

- Breastfeeding provides health benefits to both the infant and mother.

- Although the majority of mothers in the United States begin breastfeeding, many are not breastfeeding for as long as they would like.

- Hospital policies and practices to support breastfeeding are important for improving breastfeeding rates and helping women meet their own breastfeeding goals.

- The percentage of hospitals implementing more than half of the Ten Steps to Successful Breastfeeding increased from $28.7 \%$ in 2007 to $53.9 \%$ in 2013.

- Facilities providing maternity care need to adopt evidencebased practices to support breastfeeding. Government and public health agencies can help by working with hospitals to achieve Baby-Friendly designation.

- Additional information is available at http://www.cdc. gov/vitalsigns.

289 (9\%) of the approximately 3,300 U.S. birth facilities were designated Baby-Friendly. $\$ \$ \$$ Several CDC efforts are underway to continue supporting improvements in maternity care, including continuation of the mPINC survey, the EMPower breastfeeding project 99 to support up to 100 hospitals in achieving Baby-Friendly designation, and continued support of state health departments to support breastfeeding initiatives.

\footnotetext{
$\$ \mathbb{S}$ Available at https://www.babyfriendlyusa.org/find-facilities/ designated-facilities--by-state.

999 Available at http://empowerbreastfeeding.org.
}

\footnotetext{
${ }^{1}$ Division of Nutrition, Physical Activity, and Obesity, National Center for Chronic Disease Prevention and Health Promotion, CDC; ${ }^{2}$ Battelle, Columbus, Ohio; ${ }^{3}$ Department of Nutrition for Health and Development, World Health Organization.
}

Corresponding author: Cria G. Perrine, cperrine@cdc.gov, 770-488-5183.

\section{References}

1. Section on Breastfeeding. Breastfeeding and the use of human milk. Pediatrics 2012;129:e827-41.

2. CDC. Breastfeeding among U.S. children born 2000-2012, CDC National Immunization Survey. Atlanta, GA: US Department of Health and Human Services, CDC; 2015. Available at http://www.cdc.gov/ breastfeeding/data/NIS_data.

3. Ip S, Chung M, Raman G, et al. Breastfeeding and maternal and infant health outcomes in developed countries. Evid Rep Technol Assess (Full Rep) 2007;153:1-186.

4. Hauck FR, Thompson JM, Tanabe KO, Moon RY, Vennemann MM. Breastfeeding and reduced risk of sudden infant death syndrome: a metaanalysis. Pediatrics 2011;128:103-10.

5. Schwarz EB, Ray RM, Stuebe AM, et al. Duration of lactation and risk factors for maternal cardiovascular disease. Obstet Gynecol 2009;113:974-82. 
6. Bartick M, Reinhold A. The burden of suboptimal breastfeeding in the United States: a pediatric cost analysis. Pediatrics 2010;125:e1048-56.

7. Bartick MC, Stuebe AM, Schwarz EB, Luongo C, Reinhold AG, Foster EM. Cost analysis of maternal disease associated with suboptimal breastfeeding. Obstet Gynecol 2013;122:111-9.

8. Odom EC, Li R, Scanlon KS, Perrine CG, Grummer-Strawn L. Reasons for earlier than desired cessation of breastfeeding. Pediatrics 2013;131:e726-32.

9. DiGirolamo AM, Grummer-Strawn LM, Fein SB. Effect of maternitycare practices on breastfeeding. Pediatrics 2008;122(Suppl 2):S43-9.

10. World Health Organization. International code of marketing of breast milk substitutes. Geneva, Switzerland: World Health Organization; 1981.

11. Kramer MS, Chalmers B, Hodnett ED, et al.; PROBIT Study Group (Promotion of Breastfeeding Intervention Trial). Promotion of breastfeeding intervention trial (PROBIT): a randomized trial in the Republic of Belarus. JAMA 2001;285:413-20.
12. World Health Organization. Evidence for the ten steps to successful breastfeeding. Geneva, Switzerland: World Health Organization; 1998.

13. CDC. Vital signs: hospital practices to support breastfeeding - United States, 2007 and 2009. MMWR Morb Mortal Wkly Rep 2011;60:1020-5.

14. Dewey KG, Nommsen-Rivers LA, Heinig MJ, Cohen RJ. Risk factors for suboptimal infant breastfeeding behavior, delayed onset of lactation, and excess neonatal weight loss. Pediatrics 2003;112:607-19.

15. Perrine CG, Scanlon KS, Li R, Odom E, Grummer-Strawn LM. BabyFriendly hospital practices and meeting exclusive breastfeeding intention. Pediatrics 2012;130:54-60.

16. Wagner EA, Chantry CJ, Dewey KG, Nommsen-Rivers LA. Breastfeeding concerns at 3 and 7 days postpartum and feeding status at 2 months. Pediatrics 2013;132:e865-75. 


\title{
Update: Shortened Interval for Postvaccination Serologic Testing of Infants Born to Hepatitis B-Infected Mothers
}

\author{
Sarah Schillie, MD ${ }^{1}$; Trudy V. Murphy, MD ${ }^{1}$; Nancy Fenlon ${ }^{2}$; Stephen Ko, MD ${ }^{3}$; John W. Ward, MD ${ }^{1}$
}

Infants born to hepatitis B-infected mothers receive postexposure prophylaxis to reduce their risk for perinatal hepatitis $\mathrm{B}$ virus (HBV) infection (1). Postexposure prophylaxis consists of hepatitis $\mathrm{B}(\mathrm{HepB})$ vaccine and hepatitis B immune globulin administered within 12 hours of birth, followed by completion of the 3-dose or 4-dose HepB vaccine series (1). Postvaccination serologic testing (PVST) assesses an infant's response to $\mathrm{HepB}$ vaccination and has typically occurred at age 9-18 months (1). This report provides a CDC update recommending shortening the interval for PVST from age 9-18 months to age 9-12 months. Providers should order PVST (consisting of hepatitis B surface antigen [HBsAg] and antibody to $\mathrm{HBsAg}$ [anti-HBs]) for infants born to $\mathrm{HBs} A g$-positive mothers at age 9-12 months (or 1-2 months after the final dose of the vaccine series, if the series is delayed). This recommendation was prompted by the discontinuation of production of Hib/HepB vaccine (Comvax) and new data from the Enhanced Perinatal Hepatitis B Prevention Program supporting PVST 1-2 months after receipt of the last HepB vaccine dose, and at age $\geq 9$ months.

An estimated 25,000 infants are born to $\mathrm{HBsAg}$-positive mothers each year in the United States (2). Perinatal HBV infection, acquired in utero or during delivery, results in chronic HBV infection in $90 \%$ of infected infants (1). Approximately $25 \%$ of infants with $\mathrm{HBV}$ infection acquired perinatally will die prematurely as a result of complications of cirrhosis or liver cancer (1). Before the widespread availability of postexposure prophylaxis, up to $90 \%$ of infants born to HBsAg-positive mothers developed HBV infection (1). Postexposure prophylaxis is highly effective in preventing perinatal HBV transmission. In recent years in the United States, approximately $1 \%$ of infants receiving postexposure prophylaxis develop infection (3).

PVST consists of two tests: measurement of HBsAg and anti-HBs (1). Infants born to HBsAg-positive mothers who are $\mathrm{HBsAg}$ negative with anti-HBs levels $\geq 10 \mathrm{mIU} / \mathrm{mL}$ after having received a complete, 3-dose or 4-dose HepB vaccine series are identified as vaccine responders and considered seroprotected $(4,5)$. Infants who are $\mathrm{HBsAg}$ negative with anti-HBs levels $<10 \mathrm{mIU} / \mathrm{mL}$ require revaccination with a second 3-dose HepB vaccine series, followed by retesting for anti-HBs 1-2 months after the final vaccine dose (4).

Postvaccination seroprotection is achieved in $98 \%$ of healthy full-term infants who received a 3-dose or 4-dose HepB vaccine series, although it is lower among infants with birthweights $<4.4 \mathrm{lbs}(<2,000 \mathrm{~g})$ (5). Vaccine efficacy studies have demonstrated protection against acute and chronic hepatitis B disease in immunocompetent vaccine responders (๑). Anti-HBs levels following vaccination decline over time ( $($ ). Immunocompetent persons who achieve an anti-HBs level $\geq 10 \mathrm{mIU} / \mathrm{mL} 1-2$ months after a complete HepB series remain protected, even if anti-HBs levels decline to $<10 \mathrm{mIU} / \mathrm{mL}$ beyond that time, presumably because of persistent cellular immunity ( 7 ).

HepB vaccine doses subsequent to the monovalent HepB vaccine birth dose are administered as either monovalent or combination vaccine (1). Before December 31, 2014, two combination vaccines containing recombinant $\mathrm{HBsAg}$ were available in the United States for infants aged $\geq 6$ weeks: 1) Hib/HepB vaccine (Comvax, Merck and Co, Inc.) and 2) DTaP-HepB-IPV vaccine (Pediarix, GlaxoSmithKline Biologicals) (1). Hib/HepB vaccine (Comvax) production has been discontinued. For infants born to HBsAg-positive mothers, the final dose of the HepB vaccine series is administered at age 6 months when monovalent or DTaP-HepB-IPV vaccine (Pediarix) is used to complete the series (I). When $\mathrm{Hib} / \mathrm{HepB}$ vaccine (Comvax) was used to complete the series, the final dose was administered at age 12-15 months (1).

The optimal timing for PVST to detect a vaccine response generally is $1-2$ months after the final dose of the HepB vaccine series (1). Results of tests for HBsAg can be transiently positive for 1-18 days after vaccination. PVST should be performed no earlier than age 9 months to avoid detection of passive anti-HBs from hepatitis B immune globulin administered at birth and to maximize the likelihood of detecting late HBV infection (1).

In developing this update to shorten the interval for PVST to age 9-12 months, CDC subject matter experts reviewed the shortened interval with professionals from academia and public health and considered existing (8) and new data (9) on anti-HBs levels among infants born to $\mathrm{HBsAg}$-positive mothers. Among 348 infants born to $\mathrm{HBsAg}$-positive mothers enrolled in the Enhanced Surveillance: Perinatal Hepatitis B Program in Dallas County, Texas, PVST performed at 4-7 months and 8-11 months after the final vaccine dose was associated with lower anti-HBs levels (odds ratios $=1.8$ and 4.4, respectively; $95 \%$ confidence intervals $=1.2-2.8$ and $1.3-14.5$, respectively), when compared with PVST 1-3 months after vaccination (8). In a study analyzing data collected from 8,105 HBsAgnegative infants born to $\mathrm{HBs} \mathrm{Ag}$-positive mothers enrolled in 
the Enhanced Perinatal Hepatitis B Prevention Program in five U.S. jurisdictions during 2008-2013, the percentages of tested infants with anti-HBs levels $<10 \mathrm{mIU} / \mathrm{mL}$ at ages $1-2$ months, 3-4 months, 5-6 months, 7-8 months, 9-10 months, 11-12 months, $13-14$ months and 15-16 months after the final HepB vaccine dose were $2 \%$ ( 31 of 1573 ), $2.8 \%$ ( 86 of 3,110 ), $5.1 \%$ (91 of 1,769), $7.8 \%$ (55 of 705), 9.3\% (43 of 463), $13.3 \%$ (32 of 240), 16.3\% (21 of 129) and 21.6\% (25 of 116), respectively ( $<<0.01$, Mantel-Haenszel chi-square) (Figure) (9). Nearly one fourth $(22.3 \%)$ of infants underwent PVST $>6$ months after the final vaccine dose (9).

For most infants born to HBsAg-positive mothers, PVST at age 9-12 months provides opportunities for testing at two well-child visits (i.e., 9-month and 12-month visits). An added benefit of a shortened interval to PVST is a reduction in the period during which nonresponders are at risk for transmission from close contacts with HBV infection. Earlier PVST enables prompt revaccination of those infants needing revaccination with a second 3-dose $\mathrm{HepB}$ vaccine series to attain protective anti-HBs levels. A shortened interval might also increase adherence with recommendations for timely completion of PVST and conserve public health resources involved in providing case management services (1).

\begin{abstract}
Summary
What recommendations are being reviewed?

Postvaccination serologic testing (PVST) is recommended for infants born to hepatitis B surface antigen (HBsAg)-positive mothers at age 9-18 months. PVST consists of testing for HBsAg and antibody to HBsAg (anti-HBs).

Why are the recommendations being reviewed now?

With the discontinuation of Hib/HepB vaccine (Comvax), the hepatitis $B$ vaccine series for infants born to $\mathrm{HBsAg}$-positive mothers will usually be completed at age 6 months, allowing PVST at age 9-12 months. New data from the Enhanced Perinatal Hepatitis B Prevention Program are available that show that lower detectable levels of anti-HBs were associated with increased intervals between receipt of the last vaccine dose and PVST.

What is the new recommendation?

Considering the lower levels of anti-HBs with increasing time since completing vaccination and the extent of unnecessary revaccination, PVST, consisting of testing for $\mathrm{HBsAg}$ and anti-HBs, should be ordered at age 9-12 months (or 1-2 months after the final dose of the vaccine series, if delayed) for infants born to HBsAg-positive mothers.
\end{abstract}

FIGURE. Proportion of infants with anti-HBs $\geq 10 \mathrm{mIU} / \mathrm{mL}$ with increasing interval from final vaccine dose*

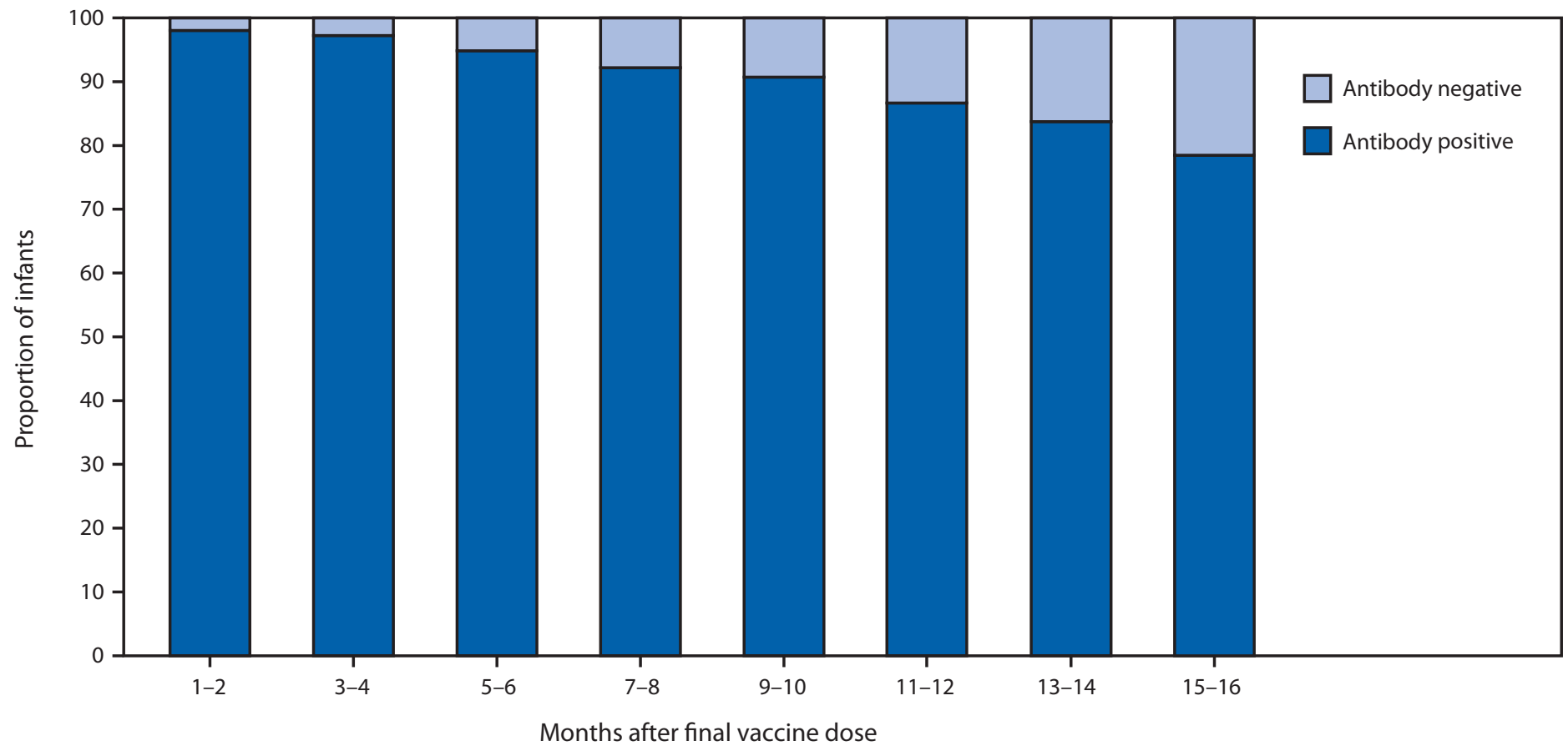

Source: Reprinted with permission of publisher from: Ko SC, Schillie SF, Walker T, et al. Hepatitis B vaccine response among infants born to hepatitis B surface antigenpositive women. Vaccine 2014;32:2127-33.

${ }^{*} \mathrm{p}<0.01$, Mantel-Haenszel chi square. 
In light of the lower measured anti-HBs levels (but continued protection) with increasing time following vaccination, PVST occurring at increasing intervals after the final vaccine dose could result in misclassification of some infants as vaccine nonresponders and therefore lead to unnecessary revaccination (9). Because nonresponding infants receive a second 3-dose HepB vaccine series followed by retesting of anti-HBs, testing soon after completion of the initial vaccine series reduces the possibility for misclassification and unnecessary revaccination (9). The PVST interval after the final dose in the primary HepB series no longer needs to extend to 18 months to accommodate infants completing their vaccination series with $\mathrm{Hib} / \mathrm{HepB}$ vaccine (Comvax). Although no data are available, CDC subject matter experts postulate that harm will not occur as a result of a shortened PVST interval. PVST (consisting of HBsAg and anti-HBs) for infants born to HBsAg-positive mothers should be performed at age 9-12 months, or 1-2 months after the final dose of the HepB vaccine series if completion of the series is delayed.

${ }^{1}$ Division of Viral Hepatitis, National Center for HIV/AIDS, Viral Hepatitis, STD, and TB Prevention, CDC; ${ }^{2}$ Immunization Services Division, National Center for Immunization and Respiratory Diseases, CDC; ${ }^{3}$ Boston University School of Public Health and School of Medicine, Massachusetts.

Corresponding author: Sarah Schillie, sschillie@cdc.gov, 404-718-8608.

\section{References}

1. Mast EE, Margolis HS, Fiore AE, et al. A comprehensive immunization strategy to eliminate transmission of hepatitis B virus infection in the United States: recommendations of the Advisory Committee on Immunization Practices (ACIP) part 1: immunization of infants, children, and adolescents. MMWR Recomm Rep 2005;54(No. RR-16).

2. Smith EA, Jacques-Carroll L, Walker TY, Sirotkin B, Murphy TV. The national Perinatal Hepatitis B Prevention Program, 1994-2008. Pediatrics 2012;129:609-16.

3. Kubo A, Shlager L, Marks AR, et al. Prevention of vertical transmission of hepatitis B: an observational study. Ann Intern Med 2014;160:828-35.

4. CDC. Postvaccination serologic testing results for infants aged $\leq 24$ months exposed to hepatitis B virus at birth: United States, 2008-2011. MMWR Morb Mortal Wkly Rep 2012;61:768-71.

5. Schillie SF, Murphy TV. Seroprotection after recombinant hepatitis B vaccination among newborn infants: a review. Vaccine 2013;31:2506-16.

6. Schillie S, Murphy TV, Sawyer M, et al. CDC guidance for evaluating health-care personnel for hepatitis $\mathrm{B}$ virus protection and for administering postexposure management. MMWR Recomm Rep 2013;62(No. RR-10).

7. Leuridan E, Van Damme P. Hepatitis B and the need for a booster dose. Clin Infect Dis 2011;53:68-75.

8. Euler GL, Copeland JR, Rangel MC, Williams WW. Antibody response to postexposure prophylaxis in infants born to hepatitis B surface antigenpositive women. Pediatr Infect Dis J 2003;22:123-9.

9. Ko SC, Schillie SF, Walker T, et al. Hepatitis B vaccine response among infants born to hepatitis B surface antigen-positive women. Vaccine 2014;32:2127-33. 


\section{Severe IIIness Associated with Reported Use of Synthetic Cannabinoids - Mississippi, April 2015}

Amelia M. Kasper, MD ${ }^{1,2}$; Alison D. Ridpath, MD²; Justin K. Arnold, $\mathrm{DO}^{3}$; Kevin Chatham-Stephens, $\mathrm{MD}^{1,2}$; Melissa Morrison, $\mathrm{MPH}^{4}$; Olaniyi Olayinka, $\mathrm{MD}^{1,2}$; Christina Parker ${ }^{5}$; Robert Galli, $\mathrm{MD}^{6}$; Robert Cox, MD, PhD ${ }^{5}$; Nykiconia Preacely, $\mathrm{DrPH}^{4,7}$; Jannifer Anderson ${ }^{7}$; Patrick B. Kyle, $\mathrm{PhD}^{6}$; Roy Gerona, $\mathrm{PhD}^{8}$; Colleen Martin, $\mathrm{MSPH}^{2}$; Josh Schier, $\mathrm{MD}^{2}$; Amy Wolkin, $\mathrm{DrPH}^{2}$; Thomas Dobbs, $\mathrm{MD}^{7}$

On April 2, 2015, four patients were evaluated at the University of Mississippi Medical Center (UMMC) in Jackson, Mississippi, for agitated delirium after using synthetic cannabinoids. Over the next 3 days, 24 additional persons went to UMMC with illnesses suspected to be related to synthetic cannabinoid use; one patient died. UMMC notified the Mississippi State Department of Health, which issued a statewide alert via the Health Alert Network on April 5, requesting that health care providers report suspected cases of synthetic cannabinoid intoxication to the Mississippi Poison Control Center (MPCC). A suspected case was defined as the occurrence of at least two of the following symptoms: sweating, severe agitation, or psychosis in a person with known or suspected synthetic cannabinoid use. A second statewide alert was issued on April 13, instructing all Mississippi emergency departments to submit line lists of suspected patients to MPCC each day. By April 21, 16 days after the first alert was issued, MPCC had received reports of approximately 400 cases, including eight deaths possibly linked to synthetic cannabinoid use; in contrast, during April 2012-March 2015, the median number of telephone calls to MPCC regarding synthetic cannabinoid use was one per month (range $=0-11$ ). The Mississippi State Department of Health, with the assistance of CDC, initiated an investigation to better characterize the outbreak, identify risk factors associated with severe illness, and prevent additional illnesses and deaths.

During April 2-May 3, 2015, MPCC received reports of 721 suspected cases, including nine deaths associated with synthetic cannabinoid use. The weekly number of reports peaked at 214 reports during April 16-23. A majority of counties in the state (48 of $82[59 \%]$ ) reported at least one case. The investigative team chose the UMMC patient population as a convenience sample to better understand the characteristics of the illness. Using MPCC data, the Mississippi State Department of Health and CDC identified suspected cases among patients who received care at UMMC. The team then reviewed emergency medical service reports, electronic medical records, and MPCC records to collect information about reported synthetic cannabinoid use, initial symptoms, vital signs, physical examination findings, clinical laboratory data, illness course, treatments given, and disposition. Clinical specimens were sent to the Clinical Toxicology and Environmental Biomonitoring Laboratory at the University of California, San Francisco, for liquid chromatography-quadrupole time-of-flight mass spectrometry, which tests for 109 different synthetic cannabinoids and metabolites.

Among the 721 suspected cases, 119 (17\%) patients received care at UMMC; all 119 medical records were abstracted. Patients ranged in age from 14 to 62 years (median $=31$ years), and $101(85 \%)$ were male. Eighty-three patients (70\%) were treated and released by the UMMC emergency department. Thirteen (11\%) patients were admitted to general inpatient services, and $12(10 \%)$ were admitted to intensive care services. Three patients (3\%) died at UMMC. Vital signs information was available for 115 patients, of whom $48(42 \%)$ had tachycardia (heart rate $>100$ beats per minute), and 35 (30\%) had elevated $(>140 \mathrm{mmHg})$ systolic blood pressure. Among all 119 patients, $38(32 \%)$ exhibited aggressive or violent behavior, and 30 (25\%) showed confusion. Sixteen (13\%) patients were reported to have both agitation/aggression and depressed mental status (e.g., somnolence or unresponsiveness). Univariable analysis showed significant associations between a previous medical history of mental illness (odds ratio $=4.4$; $95 \%$ confidence interval $=1.4-14.2$ ) or substance abuse (odds ratio $=5.0 ; 95 \%$ confidence interval $=1.5-16.0)$, and more severe outcomes (intensive care admission or death).

Among 89 patients who had urine drug screen results at UMMC, 60 (67\%) were positive for tetrahydrocannabinol (THC), the main psychoactive component in cannabis. Nineteen $(21 \%)$ were positive for cocaine. Synthetic cannabinoids cannot be detected on routine, clinical urine drug screens. Among the 16 serum specimens tested at the University of California, San Francisco, to date, 10 (63\%) have tested positive for a recently described synthetic cannabinoid or one of its predicted metabolites.* Four (25\%) specimens were positive for other substances, including benzodiazepines (three), opioids (two), phencyclidine (one), and mitragynine (one), a plant-based opioid agonist that is currently legal in Mississippi. Results are pending from specimens from an additional 75 patients from UMMC and 143 patients from other Mississippi hospitals.

The current outbreak of illnesses associated with synthetic cannabinoid use in Mississippi is part of a larger, multistate

\footnotetext{
*MAB-CHMINACA (N-(1-amino-3,3-dimethyl-1-oxobutan2-yl)-1-(cyclohexylmethyl)-1H-indazole-3-carboxamide), also known as ADB-CHMINACA.
} 
outbreak (1). To date, this is the largest outbreak of synthetic cannabinoid-associated adverse events ever recorded (2-4). Synthetic cannabinoids represent a wide variety of compounds that bind with variable affinities to the cannabinoid receptor; in general, they are stronger cannabinoid receptor agonists compared with THC. The effects of synthetic cannabinoids vary by type. As novel synthetic cannabinoids continue to be developed and trafficked, health care providers, public health officials, laboratory scientists, and law enforcement officials should continue to work together to identify strategies to curb synthetic cannabinoid use, strengthen surveillance in order to detect and monitor outbreaks, and optimize patient care.

\section{Acknowledgments}

Paul Byers, MD, Theresa Kittle, MPH, Joy Sennett, MHS, Nora Truhett, Sheryl Hand, Mississippi State Department of Health; Mark LeVaughn, MD, Mississippi State Medical Examiner's Office; University of Mississippi Medical Center's Office of Integrity and Compliance; Royal Law, MPH, Division of Environmental Hazards and Health Effects, National Center for Environmental Health, CDC.
${ }^{1}$ Epidemic Intelligence Service, CDC; ${ }^{2}$ Division of Environmental Hazards and Health Effects, National Center for Environmental Health, CDC; ${ }^{3}$ Georgia Poison Center; ${ }^{4}$ Career Epidemiology Field Officer, CDC ; ${ }^{5}$ Mississippi Poison Center; ${ }^{6}$ University of Mississippi Medical Center; ${ }^{7}$ Mississippi State Department of Health; ${ }^{8}$ Department of Laboratory Medicine, University of California San Francisco.

Corresponding author: Amelia Kasper, akasper@cdc.gov, 770-488-3433.

\section{References}

1. Law R, Schier J, Martin C, et al. Notes from the field: increase in reported adverse health effects related to synthetic cannabinoids-United States, January-May 2015. MMWR Morb Mortal Wkly Rep 2015;62:618-9.

2. CDC. Notes from the field: severe illness associated with reported use of synthetic marijuana-Colorado, August-September 2013. MMWR Morb Mortal Wkly Rep 2013;62:1016-7.

3. CDC. Acute kidney injury associated with synthetic cannabinoid usemultiple states, 2012. MMWR Morb Mortal Wkly Rep 2013;62:93-8.

4. CDC. Notes from the field: severe illness associated with synthetic cannabinoid use-Brunswick, Georgia, 2013. MMWR Morb Mortal Wkly Rep 2013;62:939. 


\section{Measles in a Patient with Presumed Immunity - Los Angeles County, 2015}

\author{
Amanda Kamali, MD ${ }^{1,2}$; Chhandasi P. Bagchi, $\mathrm{MPH}^{3}$; \\ Emmanuel Mendoza, $\mathrm{MPH}^{3}$; Dulmini Wilson, $\mathrm{MPH}^{3}$; \\ Benjamin Schwartz, $\mathrm{MD}^{2}$; Laurene Mascola, $\mathrm{MD}^{2}$
}

On February 14, 2015, patient A, aged 17 years, was seen in an emergency department for evaluation of reactive airway disease. In the waiting room at the same time were two siblings, aged 6 months, presenting with fever and rash; these two children (patients B and C) were later confirmed to have measles. Patient A began a 5-day course of oral prednisone (50 mg per day); however, symptoms continued, and patient $A$ returned to the emergency department the next day and received $125 \mathrm{mg}$ of intravenous (IV) methylprednisolone. Patient A had documentation of receipt of 2 doses of measles, mumps, and rubella (MMR) vaccine at ages 12 months and 4 years.

A contact investigation was initiated by the hospital to identify all persons who might have been exposed to patient B or patient C. An infant aged 10 days was identified within the first 6 days of exposure and offered postexposure prophylaxis with intramuscular (IM) immune globulin. A second infant was identified later and was outside of the window period for immune globulin. Patient A was not identified as a susceptible contact in the investigation because of the documented history of receipt of MMR vaccine. Patients $B$ and $C$ had returned to the hospital on February 17, before receiving a diagnosis of measles, and exposed three other susceptible children (two infants aged $<12$ months and a child aged 3 years with leukemia). One infant was offered MMR vaccine, the other IM immune globulin, and the child with leukemia was offered IV immune globulin. On March 2, 16 days after the first emergency department visit, patient A was hospitalized for vomiting and dehydration. Patient $\mathrm{A}$ was also found to be febrile and to have a confluent papular rash that began on the face and spread to trunk and extremities and had small vesicular oral lesions. Measles was confirmed by laboratory testing, and patient A received supportive treatment with anti-emetics and IV fluids.

Patients A, B, and C were part of a measles outbreak originating at the Disney theme park in Orange County, California, in December 2014, which included 28 confirmed cases in Los Angeles County (1). As of April 17, 2015, a total of 136 measles cases had been documented in California, and among those, 10 patients had received at least 1 dose of MMR vaccine, 13 had received 2 doses, and two had received 3 doses (1; Jennifer Zipprich, $\mathrm{PhD}$, Kathleen Harriman, PhD, California Department of Public Health, personal communication, June 2015). Measles is highly contagious, and high levels of population immunity are required to prevent transmission to susceptible persons. MMR vaccine is highly effective, with a single dose conferring immunity in $92 \%-95 \%$ of persons (2); however, because vaccine failures do occur, a second dose of measles vaccine has been routinely recommended since 1989 (3). Complications associated with measles include pneumonia, otitis media, diarrhea, and encephalitis; postexposure prophylaxis is recommended for all susceptible contacts (2,4). MMR vaccine, if administered within 72 hours of initial measles exposure, might provide some protection or modify the clinical course of disease. Persons who are at risk for severe illness and complications from measles who cannot receive MMR vaccine, including infants aged $<12$ months, persons who are severely immunocompromised (including persons taking high-dose steroids for $\geq 2$ weeks), and persons with leukemia or lymphoma $(2,5)$, should receive prophylaxis with immunoglobulin within 6 days of exposure.

Patient A had received 2 doses of MMR vaccine and did not meet criteria for being severely immunocompromised, however, this patient did develop measles after being exposed in the setting of a hospital emergency department to patients with laboratory-confirmed measles. Although it is not known whether patient A developed immunity to measles in response to the 2 administered doses of MMR vaccine, or whether patient $A$ had an unrecognized immunocompromising condition, the recent steroid use might have weakened the patient's immune response and rendered patient A susceptible to wild measles strain. The diagnosis of measles in patient A highlights the concern that immunocompromised and susceptible persons might be exposed in a health care setting. More information is needed concerning the effect of immunomodulating drugs on vaccine-induced immunity to measles and other vaccine-preventable diseases.

\footnotetext{
${ }^{1}$ Epidemic Intelligence Service, CDC; ${ }^{2}$ Acute Communicable Disease Control, Los Angeles County Department of Public Health; ${ }^{3}$ Immunization Program, Los Angeles County Department of Public Health.

Corresponding author: Amanda Kamali, ydh3@cdc.gov, 213-240-7941.
}

\section{References}

1. California Department of Public Health. Surveillance update. Available at https://www.cdph.ca.gov/HealthInfo/discond/Documents/Measles_ update_4-17-2015_public.pdf.

2. CDC. Prevention of measles, rubella, congenital rubella syndrome, and mumps, 2013: summary recommendations of the Advisory Committee on Immunization Practices (ACIP). MMWR Recomm Rep 2013;62(No. RR-4).

3. Rosen JB, Rota JS, Hickman CJ, et al. Outbreak of measles among persons with prior evidence of immunity, New York City, 2011. Clin Infect Dis 2014;58:1205-10.

4. Perry RT, Halsey NA. The clinical significance of measles: a review. J Infect Dis 2004;189(Suppl 1):S4-16.

5. California Department of Public Health. Measles investigation quicksheet. Available at http://www.cdph.ca.gov/programs/immunize/Documents/ CDPHMeaslesInvestigationQuicksheet.pdf. 


\section{National Bullying Prevention Awareness Month - October 1-31, 2015}

Bullying is "any unwanted aggressive behavior(s) by another youth or group of youths who are not siblings or current dating partners that involves an observed or perceived power imbalance and is repeated multiple times or is highly likely to be repeated" (1). As a form of youth violence, bullying can include aggression that is physical (e.g., hitting, tripping), verbal (e.g., name calling, teasing), or relational/social (e.g., rumor spreading, leaving out of a group). Electronic aggression or cyberbullying is bullying that occurs through Internet or mobile telephone technology (e.g., e-mail, chat room, instant messaging, website, text messaging, videos, or pictures) (2).

Bullying is widespread in the United States. In 2013, 20\% of U.S. high school students reported being bullied on school property and 15\% reported that they were bullied electronically within the past 12 months (3). Youths who are bullied are at increased risk for depression, anxiety, sleep difficulties, and poor school adjustment (4). Youths who bully others are at increased risk for substance use, academic problems, and violence later in life (4).

October is National Bullying Prevention Awareness Month. During this month, multisectoral partners collaborate to raise awareness about bullying prevention and identify ways to stop bullying year-round through events, activities, outreach, and education. The ultimate goal is to stop bullying before it starts. Certain promising school-based bullying prevention programs include the following elements: 1) improving supervision of students, 2) using school rules and behavior management techniques to detect and address bullying, 3) implementing and consistently enforcing schoolwide anti-bullying policies, and 4) promoting cooperation among different professionals and between school staff and parents (5).

Additional information is available at http://www.cdc.gov/ violenceprevention/youthviolence/bullyingresearch/index. html and http://StopBullying.gov.

\section{References}

1. Gladden RM, Vivolo-Kantor AM, Hamburger ME, Lumpkin CD. Bullying surveillance among youths: uniform definitions for public health and recommended data elements, Version 1.0. Atlanta, GA: National Center for Injury Prevention and Control, CDC and US Department of Education; 2013. Available at http://www.cdc.gov/violenceprevention/ pdf/bullying-definitions-final-a.pdf.

2. David-Ferdon C, Hertz MF. Electronic media and youth violence: a CDC issue brief for researchers. Atlanta, GA: US Department of Health and Human Services, CDC; 2009. Available at http://www.cdc.gov/ violenceprevention/pdf/Electronic_Aggression_Researcher_Brief-a.pdf.
3. Kann L, Kinchen S, Shanklin SL, et al. Youth risk behavior surveillanceUnited States, 2013. MMWR Surveill Summ 2014;63(No. SS-4).

4. Farrington D, Baldry A. Individual risk factors for school bullying. J Aggress Conflict Peace Res 2010;2:4-16.

5. Farrington DP, Ttofi MM. School-based programs to reduce bullying and victimization. Systematic review for the Campbell Collaboration Crime and Justice Group; 2010. Available at http://www.ncjrs.gov/pdffiles1/nij/ grants/229377.pdf.

\section{Global Handwashing Day — October 15, 2015}

October 15, 2015, marks the 8th annual Global Handwashing Day. This observance increases awareness and understanding of handwashing with soap as an effective and affordable way to prevent disease around the world.

Handwashing with soap has an important role in child survival and health. About 1.8 million children aged $<5$ years die each year from diarrheal diseases and pneumonia, the top two causes of death among young children globally (1). Handwashing with soap can reduce the incidence of diarrhea among this age group by about $30 \%$ (2) and respiratory infections by about $20 \%$ (3).

Although persons around the world clean their hands with water, very few use soap to wash their hands because soap and water for handwashing might be less accessible in developing countries. Even when soap is available, it might be reserved primarily for laundry and bathing instead of for handwashing. Washing hands with soap removes bacteria much more effectively (4).

Additional information on Global Handwashing Day and handwashing in general is available from CDC at http://www. cdc.gov/handwashing. Information on water-related hygiene is available at http://www.cdc.gov/healthywater/hygiene.

\section{References}

1. Liu L, Johnson HL, Cousens S, et al. Child Health Epidemiology Reference Group of WHO and UNICEF. Global, regional, and national causes of child mortality: an updated systematic analysis for 2010 with time trends since 2000. Lancet 2012;379:2151-61.

2. Ejemot-Nwadiaro RI, Ehiri JE, Arikpo D, Meremikwu MM, Critchley JA. Hand washing promotion for preventing diarrhoea. Cochrane Database Syst Rev 2015;9:CD004265[Epub ahead of print].

3. Aiello AE, Coulborn RM, Perez V, Larson EL. Effect of hand hygiene on infectious disease risk in the community setting: a meta-analysis. Am J Public Health 2008;98:1372-81.

4. Burton M, Cobb E, Donachie P, Judah G, Curtis V, Schmidt WP. The effect of handwashing with water or soap on bacterial contamination of hands. Int J Environ Res Public Health 2011;8:97-104. 


\section{Death Rates* for Teens Aged 15-19 Years, by Sex - National Vital Statistics System, United States, 1999-2013}

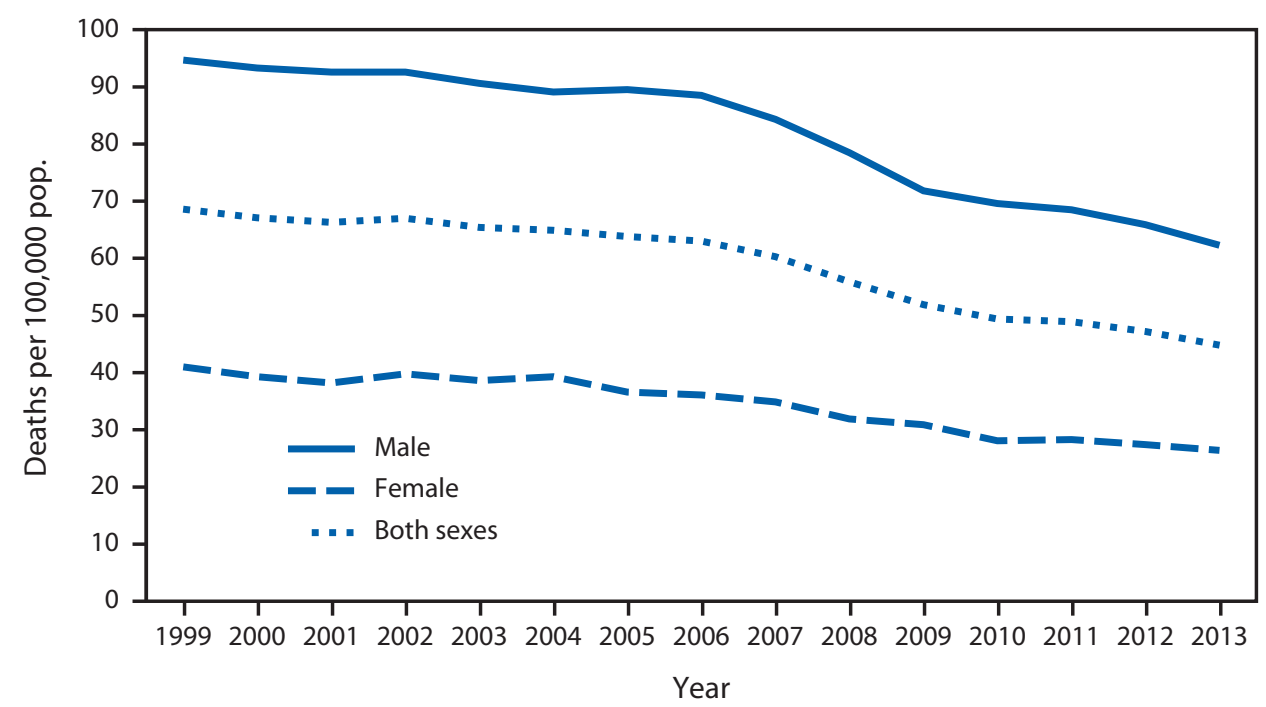

\footnotetext{
* Age-specific rates per 100,000 population among persons aged 15-19 years. Among persons in this age group, the three leading causes of death in 2013 were unintentional injuries (including motor vehicle), suicide, and homicide, which together accounted for approximately $70 \%$ of all deaths.
}

The overall death rate for teens aged 15-19 years, decreased 34.7\% from 68.6 per 100,000 population in 1999 to 44.8 in 2013. The rate of decrease was about the same for both males and females, but throughout the period rates were higher for males. The rates in 2013 were 44.8 per 100,000 population overall, 62.3 for males, and 26.4 for females in the age group.

Source: CDC. Underlying cause of death 1999-2013. CDC WONDER. Atlanta, GA: US Department of Health and Human Services, CDC; released 2015. Available at http://wonder.cdc.gov/.

Reported by: Arialdi M. Minino, MPH, 301-458-4376, aminino@cdc.gov. 


The Morbidity and Mortality Weekly Report (MMWR) Series is prepared by the Centers for Disease Control and Prevention (CDC) and is available free of charge in electronic format. To receive an electronic copy each week, visit MMWR's free subscription page at http://www.cdc.gov/mmwr/mmwrsubscribe.html. Paper copy subscriptions are available through the Superintendent of Documents, U.S. Government Printing Office, Washington, DC 20402; telephone 202-512-1800.

Readers who have difficulty accessing this PDF file may access the HTML file at http://www.cdc.gov/mmwr/index2015.html. Address all inquiries about the MMWR Series, including material to be considered for publication, to Executive Editor, MMWR Series, Mailstop E-90, CDC, 1600 Clifton Rd., N.E., Atlanta, GA 30329-4027 or to mmwrq@cdc.gov.

All material in the MMWR Series is in the public domain and may be used and reprinted without permission; citation as to source, however, is appreciated. Use of trade names and commercial sources is for identification only and does not imply endorsement by the U.S. Department of Health and Human Services.

References to non-CDC sites on the Internet are provided as a service to $M M W R$ readers and do not constitute or imply endorsement of these organizations or their programs by CDC or the U.S. Department of Health and Human Services. CDC is not responsible for the content of these sites. URL addresses listed in $M M W R$ were current as of the date of publication.

ISSN: 0149-2195 (Print) 